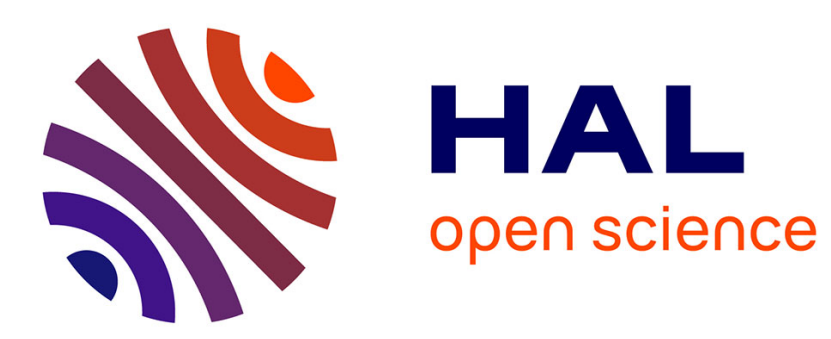

\title{
Wear characteristics of polycrystalline diamond tools in orthogonal cutting of CFRP/Ti stacks
}

\author{
Jinyang Xu, Mohamed El Mansori
}

\section{To cite this version:}

Jinyang Xu, Mohamed El Mansori. Wear characteristics of polycrystalline diamond tools in orthogonal cutting of CFRP/Ti stacks. Wear, 2017, 376-377, pp.91-106. 10.1016/j.wear.2016.11.038 . hal02417838

\section{HAL Id: hal-02417838 \\ https://hal.science/hal-02417838}

Submitted on 18 Dec 2019

HAL is a multi-disciplinary open access archive for the deposit and dissemination of scientific research documents, whether they are published or not. The documents may come from teaching and research institutions in France or abroad, or from public or private research centers.
L'archive ouverte pluridisciplinaire HAL, est destinée au dépôt et à la diffusion de documents scientifiques de niveau recherche, publiés ou non, émanant des établissements d'enseignement et de recherche français ou étrangers, des laboratoires publics ou privés. 


\title{
Wear characteristics of polycrystalline diamond tools in orthogonal cutting of CFRP/Ti stacks
}

\author{
Jinyang $\mathrm{Xu}^{\mathrm{a}, \mathrm{b}, *}$, Mohamed El Mansori ${ }^{\mathrm{b}}$ \\ a School of Mechanical Engineering, Shanghai Jiao Tong University, Shanghai 200240, PR China \\ b MSMP - EA 7350, Arts et Métiers ParisTech, Rue Saint Dominique, BP 508, Châlons-en-Champagne 51006, France
}

Keywords:

CFRP/Ti stacks

Orthogonal cutting

Wear characteristics

Tool performance

Surface quality

PCD tool

\begin{abstract}
A B S T R A C T
CFRP/Ti stacks have become a viable alternative to conventional composite laminates and metal alloys in various aerospace applications because of their enhanced mechanical properties and improved structural functions. Machining these multilayer stacks with acceptable quality still remains a great challenge for the modern manufacturing sectors due to the ineffective management of the tool wear performance resulting from the varying properties of the stacked constituents. This paper describes, on a fundamental basis, the wear characteristics of polycrystalline diamond (PCD) tipped tools during the orthogonal cutting of CFRP/Ti stacks. Two cutting sequence strategies, i.e., cutting from CFRP to Ti and cutting from Ti to CFRP, were implemented throughout the cutting tests. The experimental results confirm the predominance of the cutting sequence strategy in affecting the CFRP/Ti chip separation and the machined surface quality. The chip adhesion is a most influential factor leading to the disparate influences of the two cutting sequence strategies on the CFRP/Ti cutting responses. The PCD tool suffers severe crater wear due to the Ti phase cutting, while it undergoes minor flank wear owing to its superior wear resistance against abrasive carbon fibers. The wear signatures on the tool-chip contact zone via the scanning electron microscope (SEM) observation reveal that the Ti phase cutting dominates the formation of the tool crater wear land. The edge chipping occurs mainly due to the sudden force variation in the CFRP/Ti interface machining and the inherent brittleness of the PCD material. The fiber orientation seems to have a great impact on the wear behavior of utilized PCD tools by altering the tool-chip contact length.
\end{abstract}

\section{Introduction}

Composite/metal stacks have been widely utilized in the modern aerospace industry, and their applications in many military and commercial airplanes are consistently growing because of their improved characteristics including high strength-to-weight ratio, excellent corrosion/erosion resistance, high design flexibility, and the unique ability to withstand high stresses in service while reducing weight [1-4]. One of the representative composite/metal stacks is a CFRP/Ti sandwich consisting of one carbon fiber reinforced polymer (CFRP) laminate and one titanium (Ti) alloy. In a composite/metal structure, all the stacked materials work together

Abbreviations: BUE, built-up edge; CCD, charge coupled device; CFRP, carbon fiber reinforced polymer; EDS, energy-dispersive X-ray spectroscopy; HSS, high-speed steel; HV, Vickers hardness; PCD, polycrystalline diamond; SEM, scanning electron microscope; Ti, titanium; UD-CFRP, unidirectional carbon fiber reinforced polymer

* Corresponding author at: School of Mechanical Engineering, Shanghai Jiao Tong University, Shanghai 200240, PR China.

E-mail address: xujinyang@sjtu.edu.cn (J. Xu). or independently, but are much better than the single material they replace [2]. Many giant aircraft manufacturers such as Airbus and Boeing are widely employing these bi-material sandwiches instead of standard composites and individual metal alloys to produce competitive structural components favoring the energy saving and system improvement [5]. The primary use of these metallic-composite stacks is to strengthen or reinforce the component parts subjected to the extreme loading such as linkage sections between wing spars/ribs and the aircraft fuselage [6].

Despite their superior properties and widespread applications, CFRP/Ti stacks are difficult to cut with acceptable quality due to their anisotropic machinability related to the disparate properties of the stacked constituents [7]. Among the input parameters in machining, the tool material, tool geometry and consequent tool wear behavior are the key factors greatly influencing the cutting responses of composite/metal stacks and the machined surface quality. To date, a large number of experimental studies have been carried out to deal with the topics regarding the use of superior tool materials and functionally-designed tool geometries in the 


\begin{tabular}{|lll|}
\hline Nomenclature & $R_{q}$ & root mean squared roughness \\
& $R_{z}$ ten point mean roughness \\
CFRP $\rightarrow$ Ti cutting strategy from CFRP phase to Ti phase & $\mathrm{Ti} \rightarrow$ CFRP cutting strategy from Ti phase to CFRP phase \\
$f \quad$ feed rate & $v_{c} \quad$ cutting speed \\
$F_{c} \quad$ cutting force & $\alpha$ & tool rake angle \\
$F_{t} \quad$ thrust force & $\gamma$ & tool clearance angle \\
$R_{a} \quad$ arithmetic mean roughness & $\theta$ & fiber orientation \\
\end{tabular}

cutting of these bi-material structures. Ramulu et al. [1] were among the earliest to investigate the effects of tool materials in drilling composite/metal stacks ((Gr/Bi)/Ti) by using high-speed steel (HSS), high-speed cobalt (HSS-Co) and carbide drill bits. The experimental results indicated that the carbide drills outperformed the HSS and HSS-Co drills in terms of tool life and heatinduced damage on each stacked material. To achieve desirable hole quality, a parametric combination of low feed rates and low cutting speeds should be adopted using carbide drills, while high feed rates and low cutting speeds have to be utilized with HSS-Co drills. Besides, Isbilir and Ghassemieh [8] evaluated the tool performance of TiAlN-coated tools in drilling CFRP/Ti6Al4V stacks. They found that the TiAlN-coated drill exhibited an inferior performance in CFRP/Ti6Al4V drilling since the tool suffered serious edge chipping after drilling quite few number of CFRP/Ti holes. Tashiro et al. [9] studied the feasibility of TiAlN and TiAlCr/TiSi coated tools in drilling CFRP/Ti stacks under the dry and water-mist-cooling conditions. It was concluded that the tool life could be greatly prolonged by the use of low feed rates, and the TiAlCr/TiSi-coated drill yielded a better tool performance compared with the TiAlN-coated one due to its higher coating strength. Moreover, the functionally-designed tool geometries such as two-stage point designs [6] and special K-land designs [10] have also been demonstrated to be capable of achieving higher machined surface quality and longer tool life in drilling composite/ metal stacks.

With respect to the tool wear in cutting CFRP/Ti stacks, the experimental work done by Park et al. [2] when using the tungsten carbide and polycrystalline diamond (PCD) tools revealed that the WC drills suffered serious Ti adhesion covering the entire cutting edges, while the PCD drills underwent less Ti adhesion in the Ti alloy drilling and exhibited higher wear resistance in drilling CFRP phase. The PCD tool was found superior to the tungsten carbide one from an overall wear standpoint even though it suffered more or less edge chipping due to its inherent brittleness when drilling the Ti alloy. Furthermore, Wang et al. [3] conducted an additional investigation on the tool wear behavior in drilling CFRP/Ti stacks and their individual layers (CFRP-only and Ti-only), where the uncoated, AlTiN coated and nanocomposite coated drills were utilized. The authors pointed out that drilling CFRP/Ti could yield a longer tool life compared with drilling $\mathrm{Ti}$ alloys separately due to the prevention of the edge chipping. Besides, since the process interaction could eliminate the severe edge chipping in drilling CFRP/Ti stacks, the coated drill yielded slight advantages over the uncoated one.

In addition, machining CFRP/Ti stacks also involves the use of cutting sequence strategy, i.e., cutting from CFRP $\rightarrow$ Ti or cutting from $\mathrm{Ti} \rightarrow$ CFRP, from the aspect of tool entry and tool exit. The cutting sequence, which determines the coupling effects of each stacked phase machining, influences significantly the wear behavior of the utilized tools and the cutting characteristics of the bimaterial structure. However, very few studies on clarifying the differences between the two cutting strategies and also their effects on the tool performance in machining CFRP/Ti stacks have been reported in the available literature. Besides, although the drilling machinability of CFRP/Ti stacks has been extensively investigated in recent years, the fundamental mechanisms of orthogonal cutting these multilayer stacks still remain poorly understood.

Therefore, this paper attempts to perform a series of experiments on CFRP/Ti stacks subjected to the orthogonal cutting operation, where the complex tool-work contact features are simplified and an easy inspection of the CFRP/Ti cutting mechanisms can be achieved. The key objective of this research is to evaluate the wear characteristics of the PCD tipped inserts during the orthogonal cutting of CFRP/Ti stacks with respect to different cutting sequence strategies. To this aim, the chip separation process and cutting forces were firstly studied in order to reveal the physical mechanisms governing the influences of different cutting sequence strategies on the CFRP/Ti machinability. Afterward, the experimental analyses of the machined surface morphology, surface roughness, surface integrity (microhardness), and tool wear were performed. Finally, the influences of different cutting sequence strategies on the effectiveness of PCD tipped tools and the effects of different fiber orientations on the wear signatures of the utilized tools were clarified.

\section{Experimental procedures}

\subsection{Workpiece and tool details}

For the orthogonal cutting tests, the CFRP/Ti stacks provided by the VN Composites Company in France with the total size of 90 $\mathrm{mm}$ (length) $\times 45 \mathrm{~mm}$ (width) $\times 4 \mathrm{~mm}$ (thickness) were adopted. The CFRP/Ti specimens adopted in the present study were the same as those used in our previous research work [11], where their basic mechanical properties can be found. Three configurations of the CFRP/Ti specimens differing in fiber orientation $\left(\theta=0^{\circ}, 45^{\circ}\right.$, and $90^{\circ}$ ) were used. The stacked CFRP laminate was fabricated by the unidirectional (UD) carbon/epoxy T300/914 prepreg (60\% fiber volume fraction), while the stacked Ti alloy was the most-used Ti6Al4V. Fig. 1 depicts an overall photograph of one representative CFRP/Ti stack and also the individual microstructure of each stacked phase. It can be seen that the initial microstructure of the Ti6Al4V alloy (Ref. Fig. 1(b)) consists of the main $\alpha$ grain phase surrounded by the inclusion of $\beta$ grains. For the CFRP laminate, a distinct two-phase microstructure is clearly visible in Fig. 1(c), where the round/oval phase with an average diameter of $6.93 \mu \mathrm{m}$ and the surrounding phase represent the carbon fiber and resin matrix, respectively.

The machining tests were conducted using the polycrystalline diamond (PCD) tipped inserts (tool reference: TCMW16T304FLP CD10) provided by Sandvik Coromant. The PCD material was welded to a tungsten carbide tool substrate, comprising fine to medium-fine grain crystals with an average diameter of $7 \mu \mathrm{m}$. The details of the material composition and properties of the PCD tipped insert are summarized in Table 1. The PCD tipped insert has an effective cutting length of $7.4 \mathrm{~mm}$ with a rake angle $(\alpha)$ of $0^{\circ}$ and a clearance angle $(\gamma)$ of $7^{\circ}$. Besides, the PCD cutting zone has 


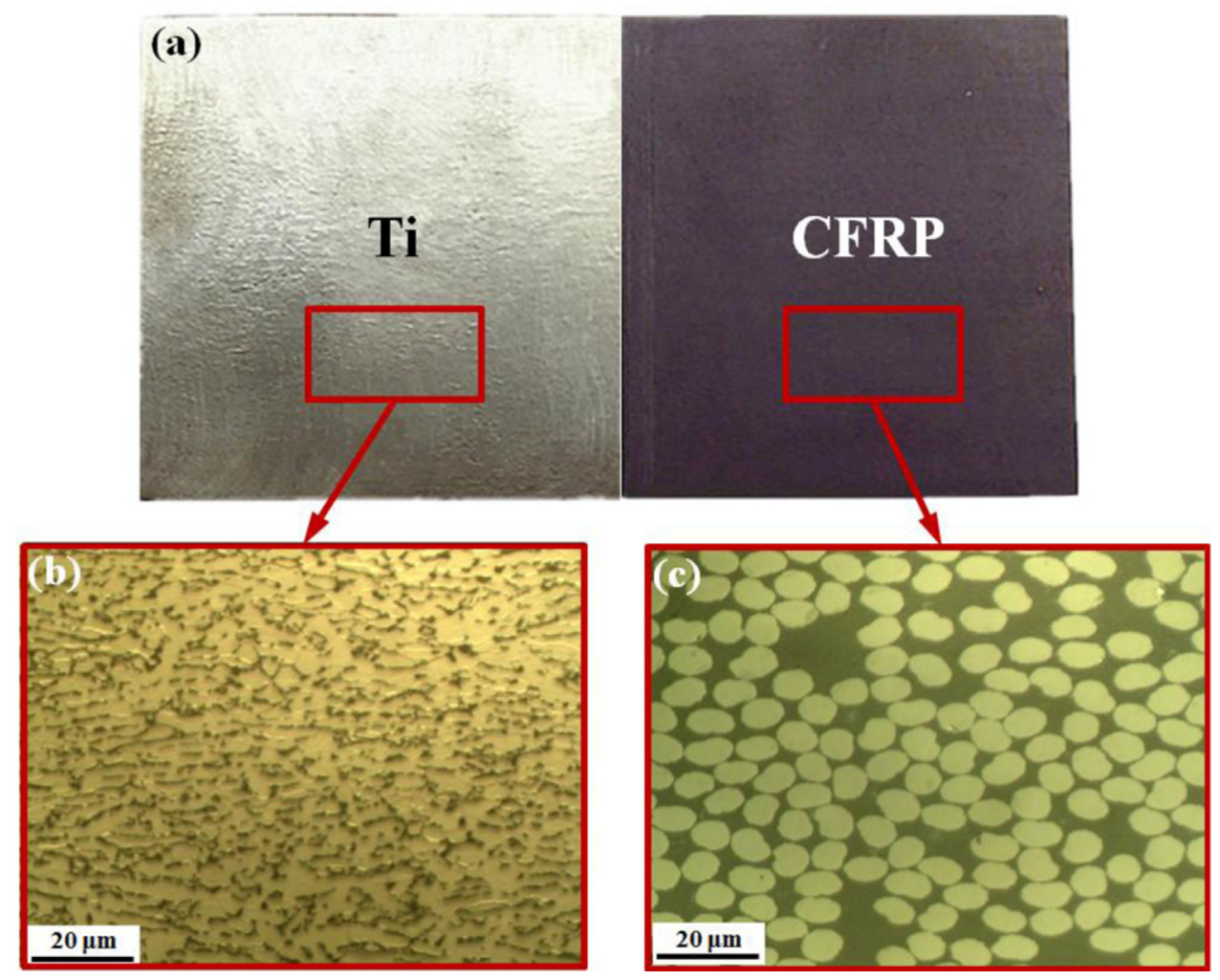

Fig. 1. (a) A photograph showing one used CFRP/Ti6Al4V specimen, (b) an optical microstructure of the Ti6Al4V phase, and (c) an optical microstructure of the CFRP phase $(\theta$ $\left.=0^{\circ}\right)$.

Table 1

Details of the used PCD tipped insert for orthogonal cutting tests.

\begin{tabular}{|c|c|c|c|c|c|}
\hline \multicolumn{6}{|c|}{ Tool material composition } \\
\hline \multicolumn{2}{|c|}{ Tool reference } & $\begin{array}{l}\text { Tipped } \\
\text { material }\end{array}$ & \multicolumn{2}{|c|}{$\begin{array}{l}\text { Diamond } \\
\text { grade }\end{array}$} & Tool substrate \\
\hline \multicolumn{2}{|c|}{ TCMW16T304FLP CD10 } & PCD & CD10 & & Tungsten carbide \\
\hline \multicolumn{6}{|c|}{ Properties of the tipped PCD material } \\
\hline Average grain size & \multicolumn{2}{|c|}{$\begin{array}{l}\text { Hardness } \\
\text { (knoops) }\end{array}$} & Density & \multicolumn{2}{|c|}{$\begin{array}{l}\text { Thermal conductivity at } \\
20^{\circ} \mathrm{C}\end{array}$} \\
\hline $7 \mu \mathrm{m}$ & \multicolumn{2}{|c|}{$50 \mathrm{GPa}$} & $4120 \mathrm{~kg} / \mathrm{m}^{3}$ & \multicolumn{2}{|c|}{$540 \mathrm{~W} /\left(\mathrm{m} \cdot{ }^{\circ} \mathrm{C}\right)$} \\
\hline
\end{tabular}

been manufactured with a very small cutting radius and a quite flat surface so as to ensure a sharp cutting edge for industrial manufacturing operations. The PCD represents one of the hardest materials, and shows high wear resistance and low friction characteristics, which can shield the tool from serious abrasive wear in composite/metal stack machining.

\subsection{Orthogonal cutting setup}

The orthogonal cutting tests were performed on a GSP-EL 136 shaper machine tool with a maximum stroke of $650 \mathrm{~mm}$ and a maximum speed of $100 \mathrm{~m} / \mathrm{min}$ under the dry cutting conditions. A photograph of the on-site experimental setup is shown in Fig. 2. During the cutting process, a piezoelectric Kistler dynamometer (type 9255B) was utilized to collect and measure the generated force signals as depicted in Fig. 2. The entire CFRP/Ti specimen was clamped manually inside the machine bearing, on the top of the Kistler dynamometer between two hard steel plates. To inspect the cutting mechanisms controlling the CFRP/Ti orthogonal cutting, the dynamic chip separation process was recorded using a high-

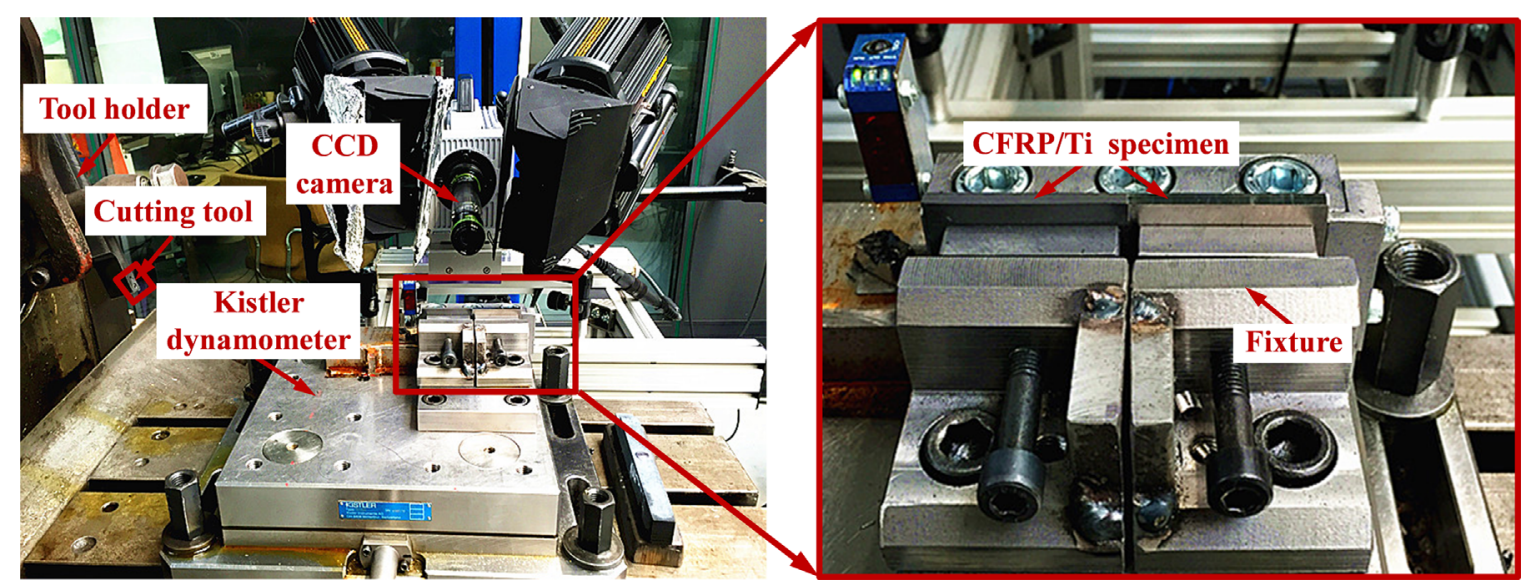

Fig. 2. Experimental setup for the orthogonal cutting of CFRP/Ti stacks. 
speed CCD camera (type FASTCAM SA5) at an acquisition rate of $20,000 \mathrm{fps}$. In addition, the high-speed camera images were captured with a particular focus on the interface region when the tool edge cuts from CFRP phase to Ti phase and vice versa. To realize the one-shot cutting of the bi-material sandwich, the identical cutting speed $\left(v_{c}\right)$ and feed rate $(f)$ were utilized to cut both the CFRP phase and the Ti phase in each machining test. Note that the feed rate $(f)$ defined in the present orthogonal cutting signifies the depth of cut. Besides, since the CFRP phase cutting and Ti phase cutting require different sets of cutting parameters, the used cutting speeds and feed rates were adopted based on a compromise selection as summarized below: $v_{c}=32,50,80 \mathrm{~m} / \mathrm{min}$, and $f=0.05$, $0.10,0.15,0.20 \mathrm{~mm} / \mathrm{rev}$. Note that during the orthogonal cutting tests, two different cutting sequence strategies (i.e., cutting from $\mathrm{CFRP} \rightarrow \mathrm{Ti}$ and cutting from $\mathrm{Ti} \rightarrow$ CFRP) were also implemented.

\subsection{Post-treatment analyses}

After the completion of the orthogonal cutting tests, the posttreatment analyses on the machined surface quality and tool wear morphologies were performed. To improve the imaging quality, the trimmed CFRP/Ti surfaces and the worn tool surfaces were cleaned by using an ultrasonic cleaning device. The machined CFRP/Ti surface morphologies were characterized using a Nikon toolmaker's SMZ-2T microscope and a JEOL JSM-5510LV scanning electron microscope (SEM). The basic specifications of the used SEM equipment are defined as follows: magnification from $\times 18$ to $\times 300,000$; modes of operation: high vacuum and low vacuum; accelerating voltage: 0.5 to $30 \mathrm{kV}$. A Veeco white-light interferometer (Wyko 3300NT) was utilized to replicate the topographic maps of the machined CFRP/Ti surface and measure the machined surface roughness. For the machined surface integrity, the microhardness of the trimmed Ti surface was examined using a microhardness Tester with a load of $100 \mathrm{gf}$ over a 10s dwell time. Each measurement was repeated three times under the identical conditions so as to get reliable results. Besides, the activated tool wear mechanisms in orthogonal cutting of CFRP/Ti stacks were investigated through both optical microscope inspections and SEM analyses. The energy-dispersive X-ray spectroscopy (EDS) studies were also performed to facilitate the chemical element analysis of the worn tool surface. The EDS analysis was conducted using the JSM-5510LV SEM equipped with an energy- dispersive X-ray spectrometer (EDS, JEOL (EUROPE) SAS, France). Finally, the wear behavior of the PCD tipped insert was also evaluated by varying the fiber orientation of the CFRP/Ti stack.

\section{Results and discussion}

\subsection{Chip removal process}

The characteristics of chip formation are of fundamental importance for understanding the responses of work materials subjected to machining operations. The chip removal process governs the machined surface quality as well as the wear behavior of utilized cutting tools. In this work, the in-situ CCD camera was used to record and analyze the dynamic characteristics of the chip formation in cutting CFRP/Ti stacks with the PCD tipped inserts. Figs. 3-5 show the recorded CFRP/Ti cutting images with respect to different fiber orientations $(\theta)$ and cutting sequence strategies. Additionally, a schematic illustration of the chip separation process versus different fiber orientations of CFRP/Ti stacks by using a $0^{\circ}$ rake angle tool is given in Table 2 . It can be seen that in machining $0^{\circ} \mathrm{CFRP} / \mathrm{Ti}$, the cutting force resulting from the tool advancement tends to initiate an interfacial debonding inside the fiber/matrix interface, causing the fiber layers to peel up and slide on the tool rake face (Ref. Table 2). Afterward, the tool movement leads the fibers to break perpendicular to their axes under buckling. In this circumstance, the real tool-chip contact length acting on the tool rake face should be slightly larger than the nominal depth of cut (i.e., the feed rate $(f)$ in the present study) as shown in Table 2. Besides, since the brittle fracture operates as a predominant chip separation mode of $0^{\circ}$ CFRP phase, various "discontinuous" chips are generally formed (Ref. Fig. 3(a)). The small chips produced in cutting are characterized by the "powdery" nature as shown in Fig. 6(a) due to a series of ruptures in the chip removal process. In addition, when cutting $45^{\circ} \mathrm{CFRP}$ in a composite/metal stack, the tool advancement causes severe compressioninduced shear among the uncut fibers, and initiates cracks in fibers above or beneath the cutting plane. Afterward, the interfacial debonding appears at the vicinity of the tool tip and propagates along the direction of the fiber orientation until completely releasing the chips. With the ongoing chip removal process, the $45^{\circ}$
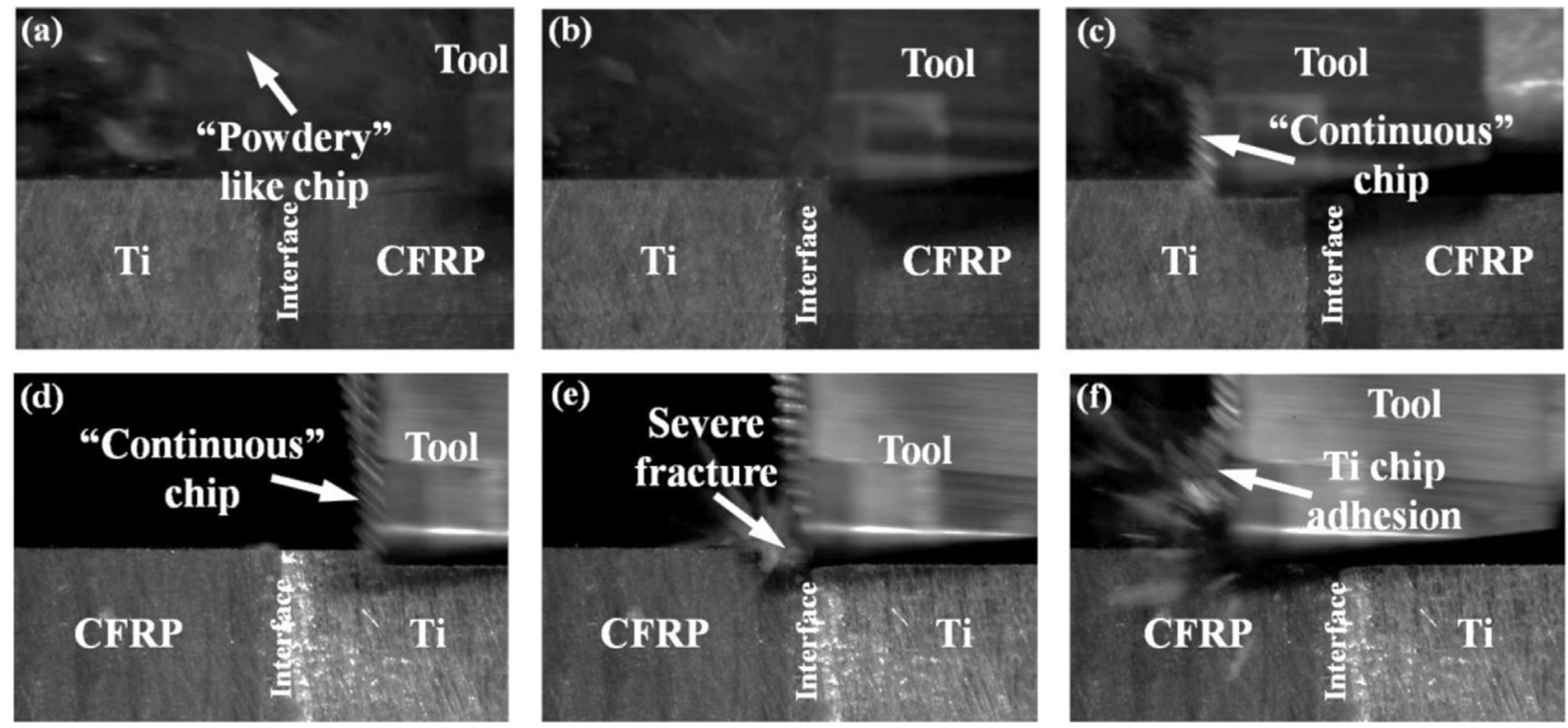

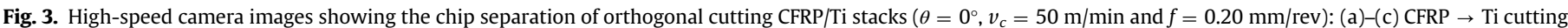
sequence and (d)-(f) Ti $\rightarrow$ CFRP cutting sequence. 

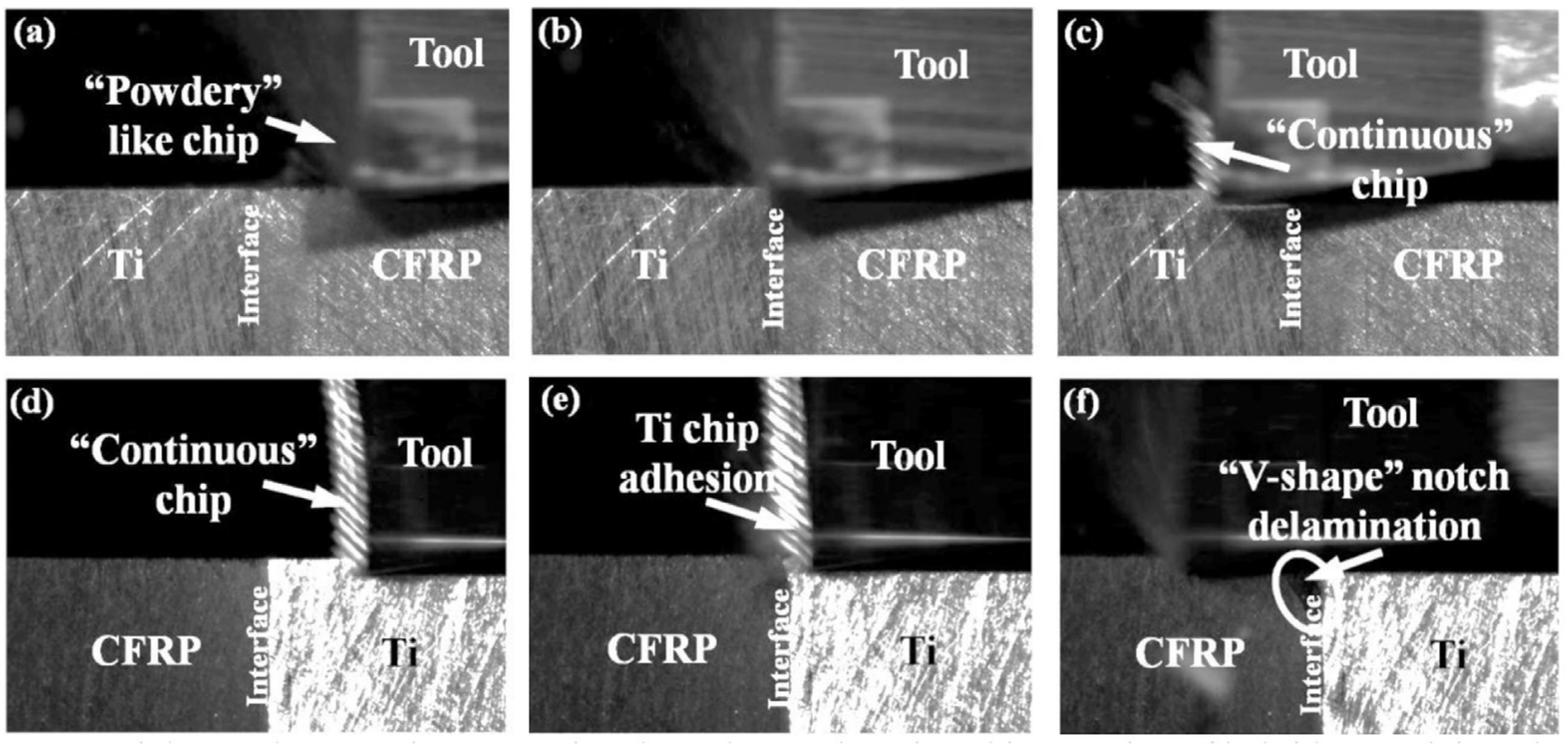

Fig. 4. High-speed camera images showing the chip separation of orthogonal cutting CFRP/Ti stacks $\left(\theta=45^{\circ}, v_{c}=50 \mathrm{~m} / \mathrm{min}\right.$ and $\left.f=0.20 \mathrm{~mm} / \mathrm{rev}\right):(\mathrm{a})-(\mathrm{c})$ CFRP $\rightarrow$ Ti cutting sequence and (d)-(f) $\mathrm{Ti} \rightarrow$ CFRP cutting sequence.

CFRP/Ti machining results in a tool-chip contact length approximately equal to the nominal depth of cut as schematically illustrated in Table 2. Moreover, when cutting a $90^{\circ} \mathrm{CFRP} / \mathrm{Ti}$ stack, the uncut fibers in the CFRP phase are subjected to serious compression loading and bending loading, leading to the interlaminar debonding [12]. As a result, the carbon fibers ahead of the tool rake face tend to undergo severe shearing as soon as the tool edge comes in contact with them, resulting in the serious fiber/matrix cracking beneath the machined surface. When the shear stress exceeds the ultimate strength of carbon fibers, it leads to the complete chip formation. The real tool-chip contact length during the $90^{\circ}$ CFRP chip separation is assumed to be far larger than the nominal depth of cut as detailed in Table 2. Through the comparative analyses, it can be concluded that the fiber orientation of the stacked CFRP phase has a great effect on the tool-chip contact length, which will consequently affect the wear behavior of the utilized tools in the multilayer stack cutting. Detailed analyses are presented in Section 3.5.

Furthermore, when the orthogonal cutting is performed in the $\mathrm{CFRP} \rightarrow$ Ti cutting sequence as exhibited in Figs. 3-5, the tool edge initially cuts into the CFRP phase and subsequently results in the "powdery" like chip formation due to the brittle-fracture dominated chip separation mode. The CFRP chips are resected basically in the form of dust (Ref. Fig. 6(a)) and spread quickly into the surrounding environment with the tool advancement (e.g., Fig. 3 (a)-(b), Fig. 4(a)-(b) and Fig. 5(a)-(b)). Further, when the tool edge cuts across the interface region, a long "continuous" chip is produced flowing through the tool rake face due to the transition of the chip removal mechanism from brittle fracture to elastic-plastic deformation. In addition, through the entire CFRP $\rightarrow$ Ti cutting inspection, neither severe chip/material cracking nor fracture phenomenon is observed in the interface zone and CFRP phase.
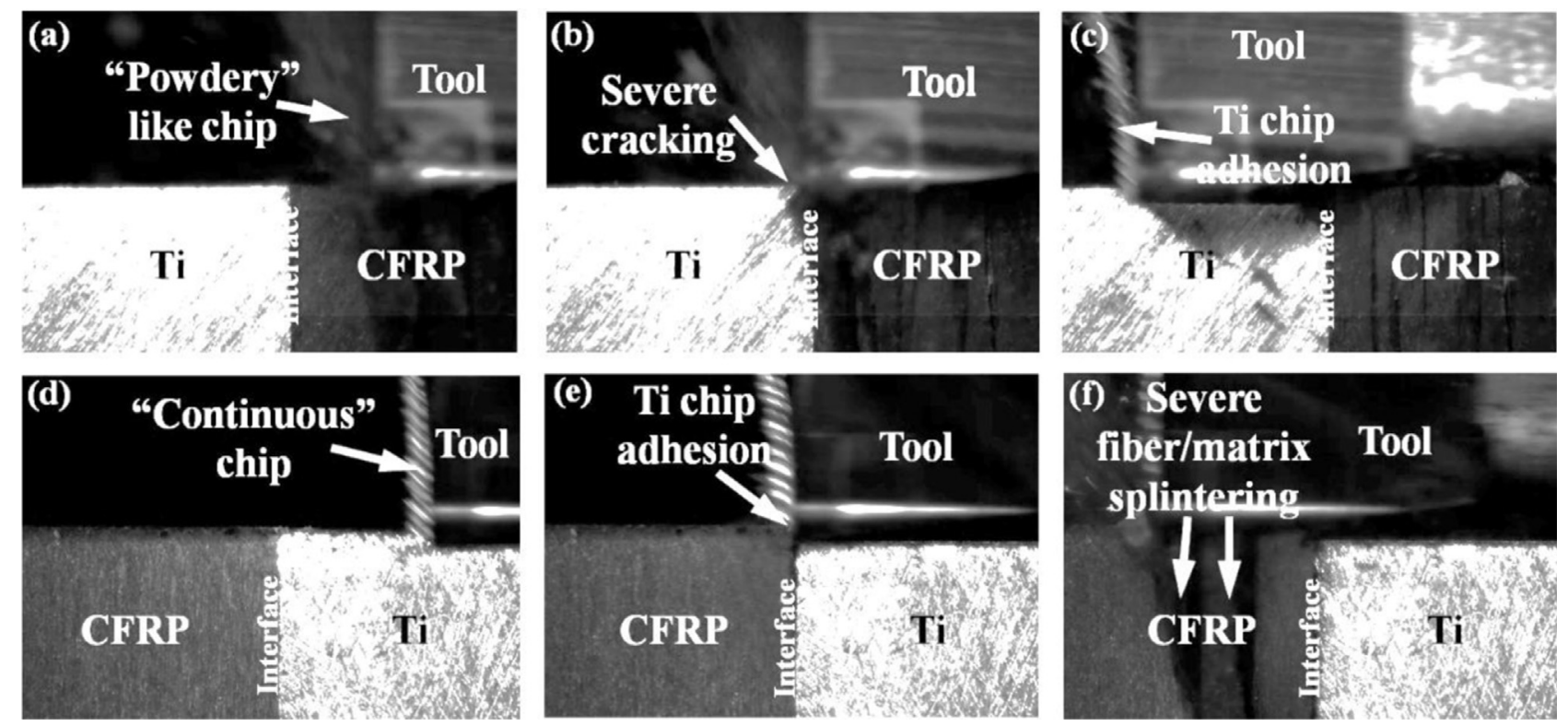

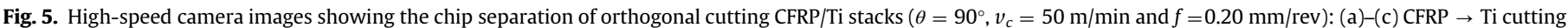
sequence and (d)-(f) Ti $\rightarrow$ CFRP cutting sequence. 
Table 2

A schematic illustration of the chip separation process with respect to different fiber orientations of CFRP/Ti stacks.

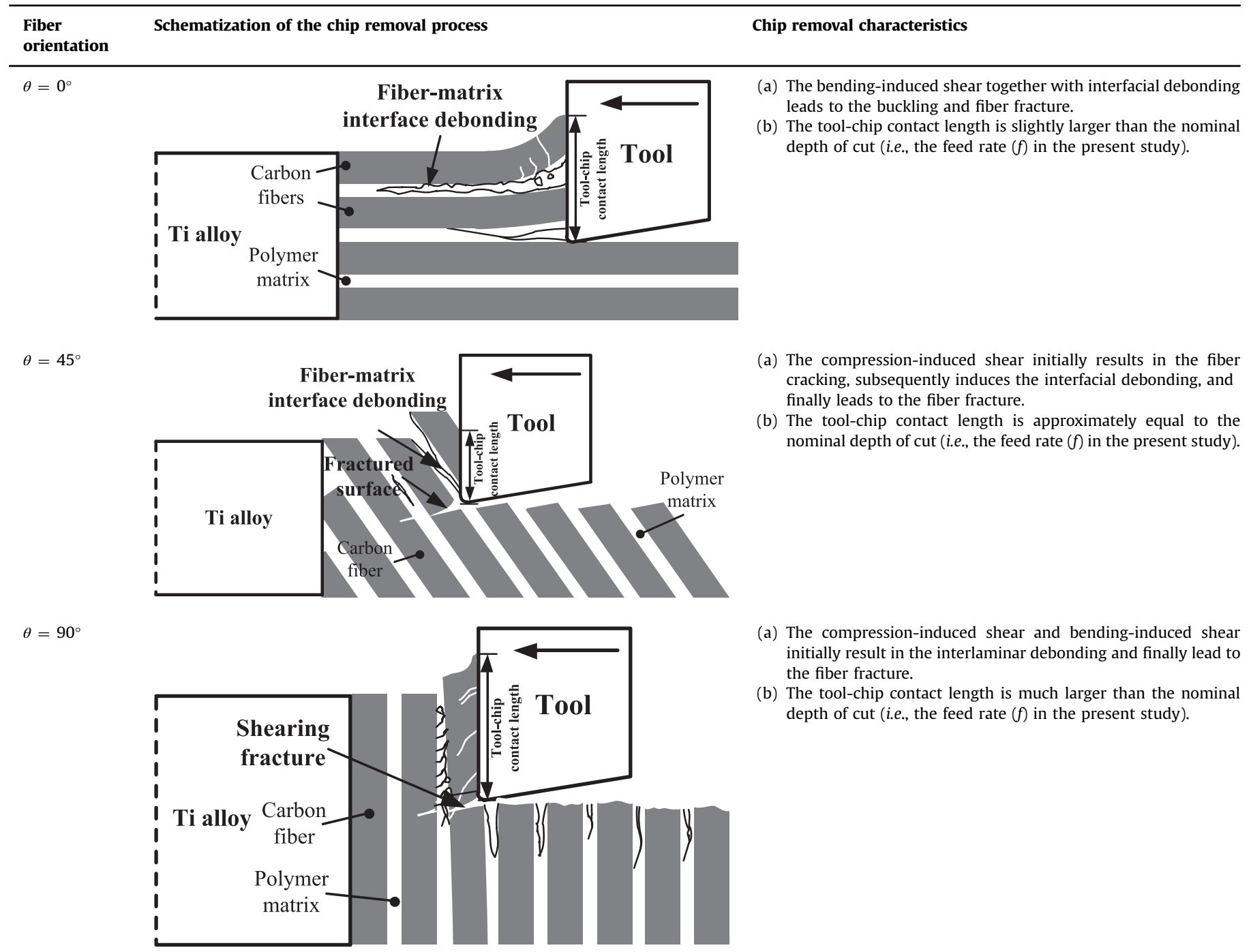
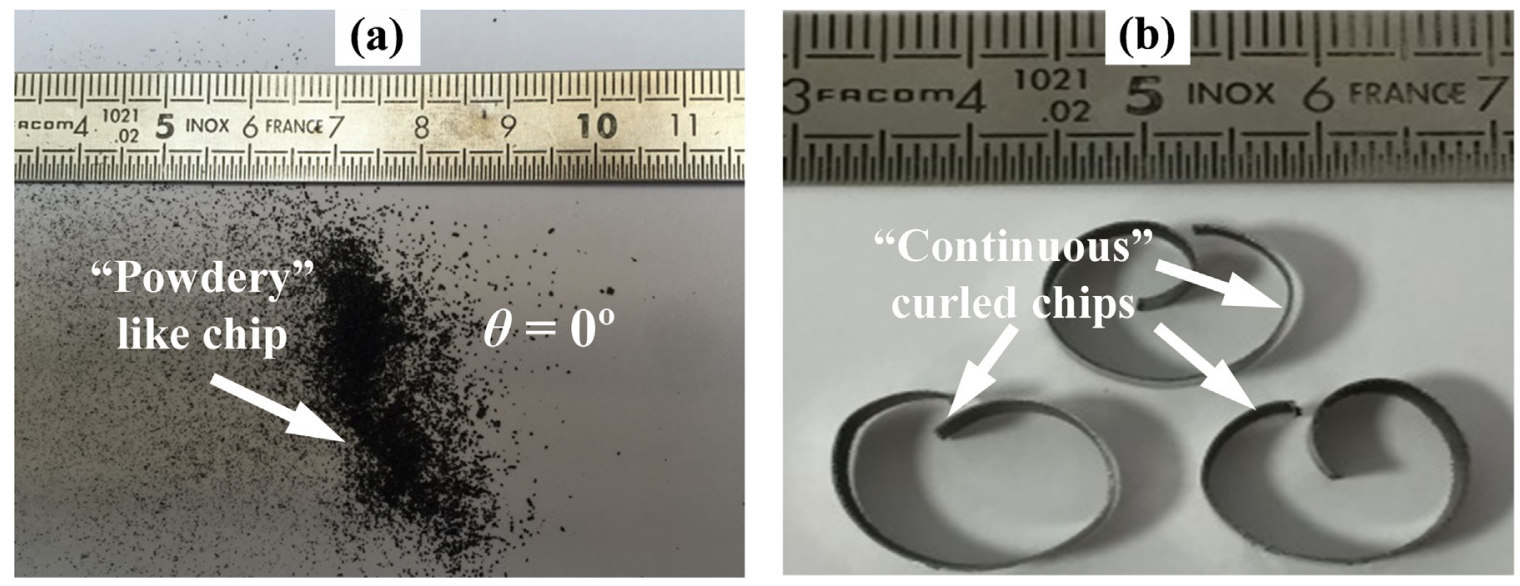

Fig. 6. Representative chip types in cutting CFRP/Ti stacks $\left(\theta=0^{\circ}, v_{c}=50 \mathrm{~m} / \mathrm{min}, f=0.20 \mathrm{~mm} / \mathrm{rev}\right.$ and CFRP $\rightarrow$ Ti cutting sequence): (a) CFRP chip type and (b) Ti chip type. 
By contrast, apart from the identically observed chip separation mode and resected chip type, the $\mathrm{Ti} \rightarrow$ CFRP cutting promotes serious cracking damage concerning the weakest interface region, as shown in Fig. 3(e). This is due to the serious Ti chip adhesion on the tool rake face that replaces the tool edge for further CFRP chip separation and hence causes significant scratching effects on the uncut CFRP chip layer. Besides, it is also identified that the problematic Ti chip adhesion occurs for all the examined fiber orientations. This detrimental phenomenon, on the one hand, should deteriorate the machined surface quality and promote the elevated cutting forces. On the other hand, it may result in the built-up edge (BUE) on tool rake face and accelerate the premature tool failure like micro chipping or edge fracture.

Moreover, the Ti $\rightarrow$ CFRP cutting is observed to promote severe subsurface damage concerning the interface zone and subsequent CFRP phase. As depicted in Fig. 4(f), when the tool edge completely cuts across the interface region, a "V-shape" notch delamination is ultimately formed in the bi-material interface. For a higher fiber orientation, e.g., $\theta=90^{\circ}$, the Ti chip adhesion has caused a larger extent of the fiber/matrix splintering beneath the machined CFRP surface as shown in Fig. 5(f) due to its severe scratching effects on the uncut CFRP chip layer.

Through the above analyses, it can be concluded that the CFRP $\rightarrow$ Ti cutting sequence globally shows a better suitability for the orthogonal cutting of CFRP/Ti stacks due to the easier chip evacuation and the avoided effects of the serious Ti chip adhesion on the subsequent CFRP machining. For the Ti $\rightarrow$ CFRP cutting, the key problem encountered in machining is the Ti chip adhesion that replaces the tool cutting edge for further CFRP phase cutting, causing detrimental influences on the CFRP/Ti surface quality.

\subsection{Cutting forces}

The force generation in the orthogonal cutting of CFRP/Ti stacks was measured in each phase machining, and each force component (cutting force $\left(F_{c}\right)$ and thrust force $\left(F_{t}\right)$ ) was calculated based on the force signals generated under the steady cutting process. Figs. 7 and 8 illustrate the obtained results with respect to different cutting conditions and cutting sequence strategies.

It is noticeable that the CFRP/Ti force variation is closely related to the utilized cutting parameters in the two cutting sequence strategies. Globally, the cutting speed $\left(v_{c}\right)$ shows an irregular impact on the force magnitudes, greatly depending on the competition between its influence on the tool wear progression and on the work material softening. This means when the influence of the cutting speed on softening the workpiece stiffness becomes a predominant factor, its impact on CFRP/Ti force generation is negative, i.e., an increased $v_{c}$ usually decreases the force magnitudes (e.g., $F_{c}$ of Ti phase cutting in Fig. 7 and $F_{c}$ of CFRP/Ti cutting in Fig. 8). On the contrary, when its effect on tool wear progression becomes a leading factor, the cutting forces decrease as $v_{c}$ increases (e.g., $F_{c}$ of CFRP phase cutting $\left(\theta=45^{\circ}\right.$ and $\left.90^{\circ}\right)$ in Fig. 7). By contrast, the feed rate $(f)$ is observed to totally have a positive impact on the CFRP/Ti cutting forces in both the CFRP $\rightarrow \mathrm{Ti}$ and Ti $\rightarrow$ CFRP cutting sequences. This can be explained by the fact that the feed rate signifies the uncut chip thickness in the present study. When the feed rate increases, the tool edge has to cut off more chip volume per cutting time, which inevitably leads to the higher cutting resistance for further chip separation and hence increases the force magnitudes.

Besides, the large cutting force $\left(F_{c}\right)$ gap between the CFRP phase cutting and Ti phase cutting as shown in Figs. 7 and 8 also implies a sudden force increase/decrease at the CFRP/Ti interface when the tool edge cuts from the CFRP phase to the Ti phase and vice versa. The physical phenomenon will inevitably lead to the severe cutting vibration and tool-work instability during the chip removal process, which may exacerbate the machined surface quality and initiate the premature tool failure like micro chipping or edge fracture.

\subsection{Machined surface morphology}

In the present study, the machined CFRP/Ti surface morphologies gained in different cutting sequences were examined. For each $\theta$ configured CFRP/Ti specimen, a new PCD tipped insert was utilized in order to prevent the tool wear influences on the trimmed surface. Fig. 9 shows the comparative SEM images of various $\theta$ configured CFRP/Ti specimens machined in the CFRP $\rightarrow$ Ti cutting sequence under the fixed cutting conditions of $v_{c}=50 \mathrm{~m} / \mathrm{min}$ and $f=0.2 \mathrm{~mm} / \mathrm{rev}$. Each SEM image was taken in the middle side of the trimmed CFRP surface, interface and Ti surface. As depicted in this figure, the machined $\mathrm{Ti}$ phase surface seems much smoother than the machined CFRP surface, irrespective of the used $\theta$ configuration. Besides, the CFRP/Ti specimen with $\theta=90^{\circ}$ configuration is produced with serious defects as depicted in Fig. 9. By comparing the acquired CFRP morphologies between three $\theta$ configured specimens $\left(\theta=0^{\circ}, 45^{\circ}\right.$, and $90^{\circ}$ ), the largest extent of the carbon fiber splintering is found along the machined CFRP surface boundary for the $90^{\circ} \mathrm{CFRP} / \mathrm{Ti}$ specimen. The SEM observation confirms that cutting higher $\theta$ configured CFRP/Ti is more likely to induce serious fiber/matrix damage on the trimmed CFRP surface boundary, where various types of defects such as

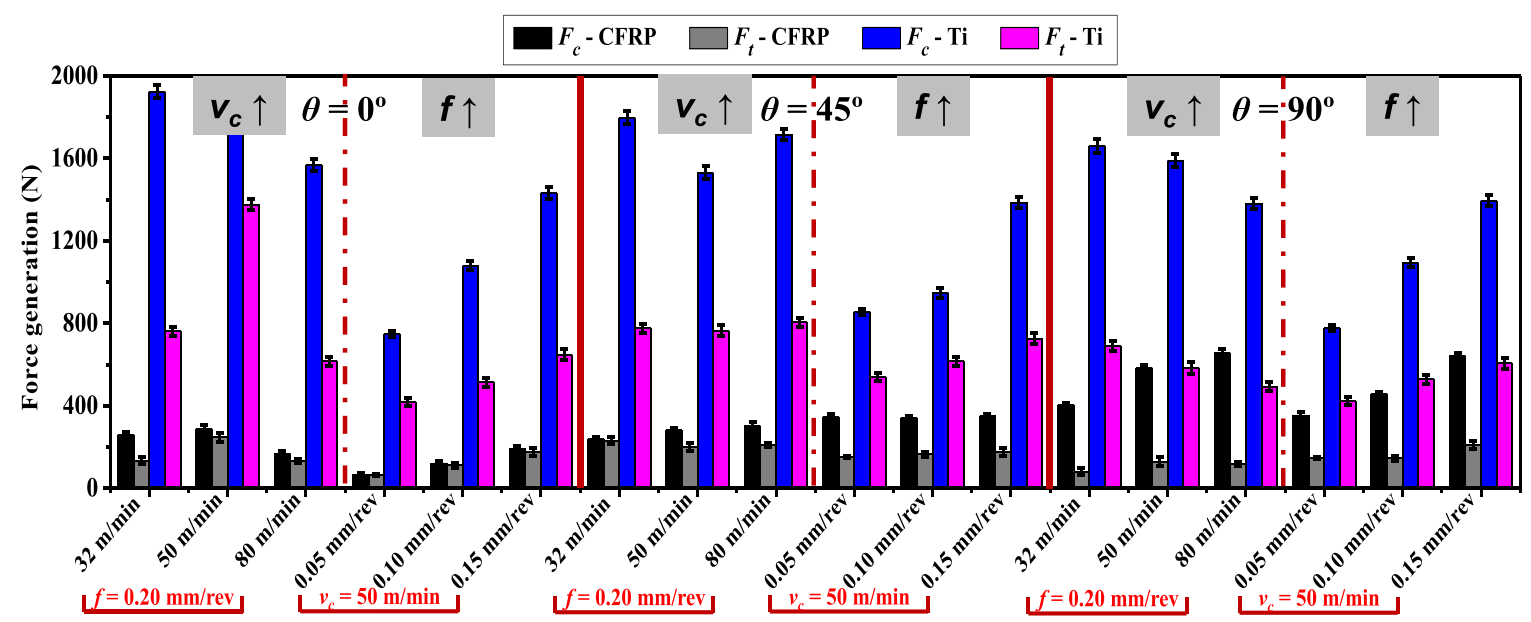

Fig. 7. Parametric effects on the cutting force $\left(F_{c}\right)$ and thrust force $\left(F_{t}\right)$ in the orthogonal cutting of CFRP/Ti stacks under the CFRP $\rightarrow$ Ti cutting sequence. 


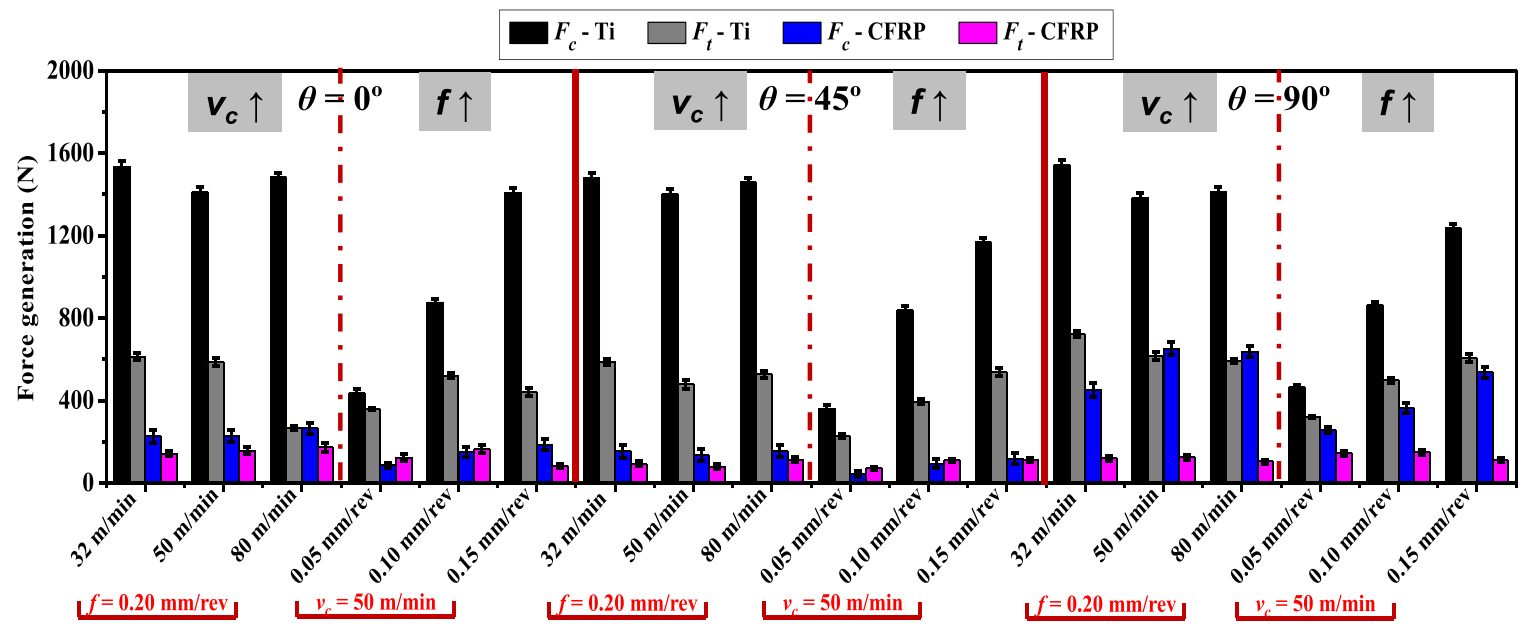

Fig. 8. Parametric effects on the cutting force $\left(F_{c}\right)$ and thrust force $\left(F_{t}\right)$ in the orthogonal cutting of CFRP/Ti stacks under the Ti $\rightarrow$ CFRP cutting sequence.

fiber splintering and resin loss become prevalent. The phenomena indicate that an increase of the fiber orientation in the CFRP/Ti stack will definitively result in serious cutting-induced damage. The activated mechanism can be attributed to the varying chip separation mode versus fiber orientation $(\theta)$, which greatly affects the machined surface morphology of the composite phase. For instance, when machining a high $\theta$ configured CFRP phase (e.g., $\theta$ $=90^{\circ}$ in the current case), the chip removal process is governed by the bending/compression separation coupled with serious out-ofplane shearing, inevitably leading to the severe subsurface damage.

In addition, the 3D topographies of the trimmed CFRP/Ti surfaces with different fiber orientations in the CFRP $\rightarrow$ Ti cutting sequence are shown in Figs. 10-12. The topographic maps were

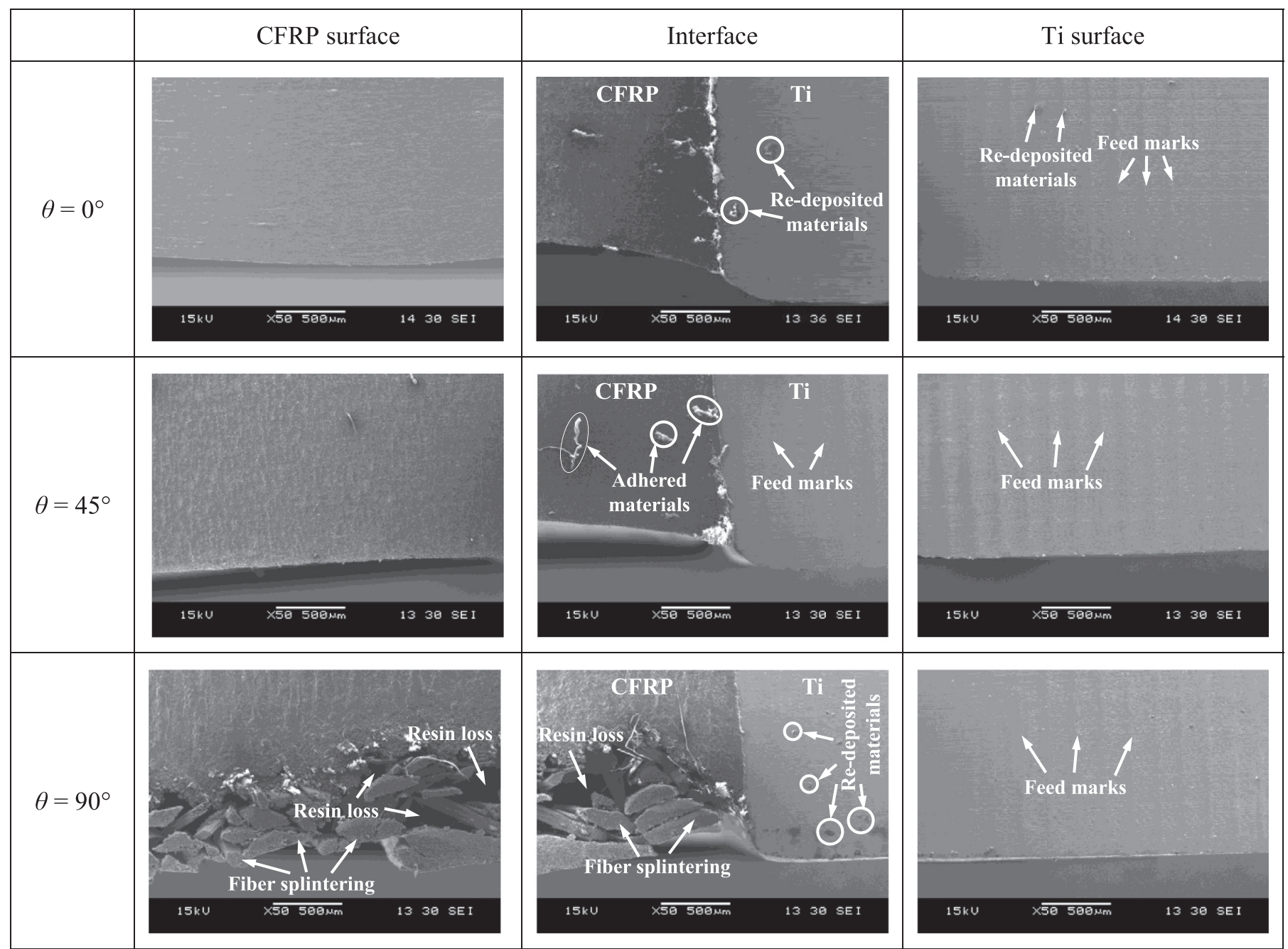

Fig. 9. Comparative SEM observations of the machined CFRP/Ti surface morphologies in the CFRP $\rightarrow$ Ti cutting sequence $\left(v_{c}=50 \mathrm{~m} / \mathrm{min}\right.$ and $\left.f=0.20 \mathrm{~mm} / \mathrm{rev}\right)$. 


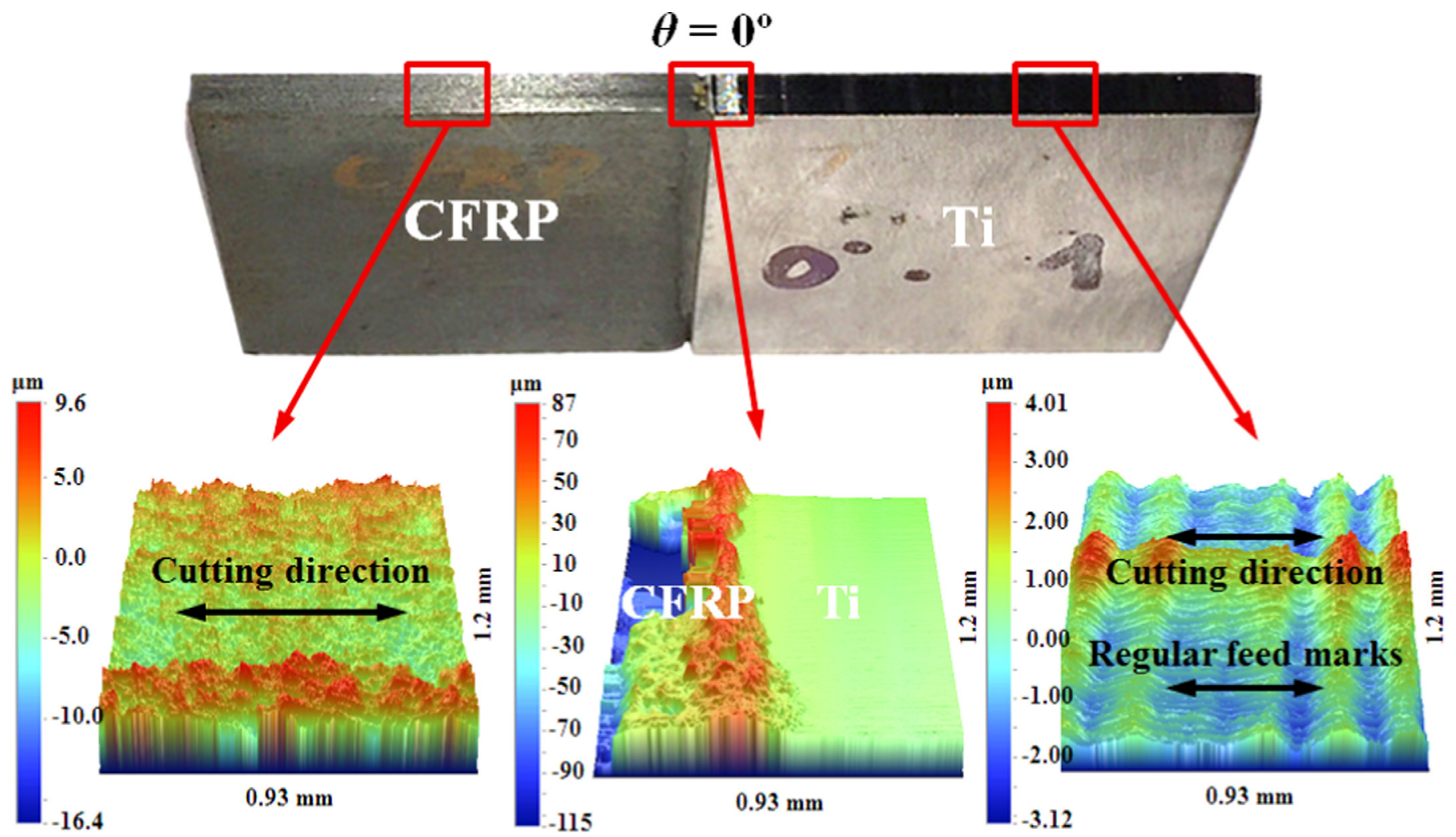

Fig. 10. Topographic maps for the trimmed CFRP/Ti surface with $0^{\circ}$ fiber orientation in the CFRP $\rightarrow$ Ti cutting sequence $\left(v_{c}=50 \mathrm{~m} / \mathrm{min}\right.$ and $\left.f=0.20 \mathrm{~mm} / \mathrm{rev}\right)$.

obtained by using the Wyko 3300NT white-light interferometer with a defined scanning area of $0.93 \mathrm{~mm} \times 1.2 \mathrm{~mm}$. Note that the topographic maps for each trimmed CFRP surface and Ti surface were recorded on the middle machined surface zone, which signifies the steady cutting zone of the work material. The topographic analyses indicate that for the machined Ti surfaces, the regular feed marks on the generated surfaces are formed, which may be caused by the varying extent of the elastic-plastic

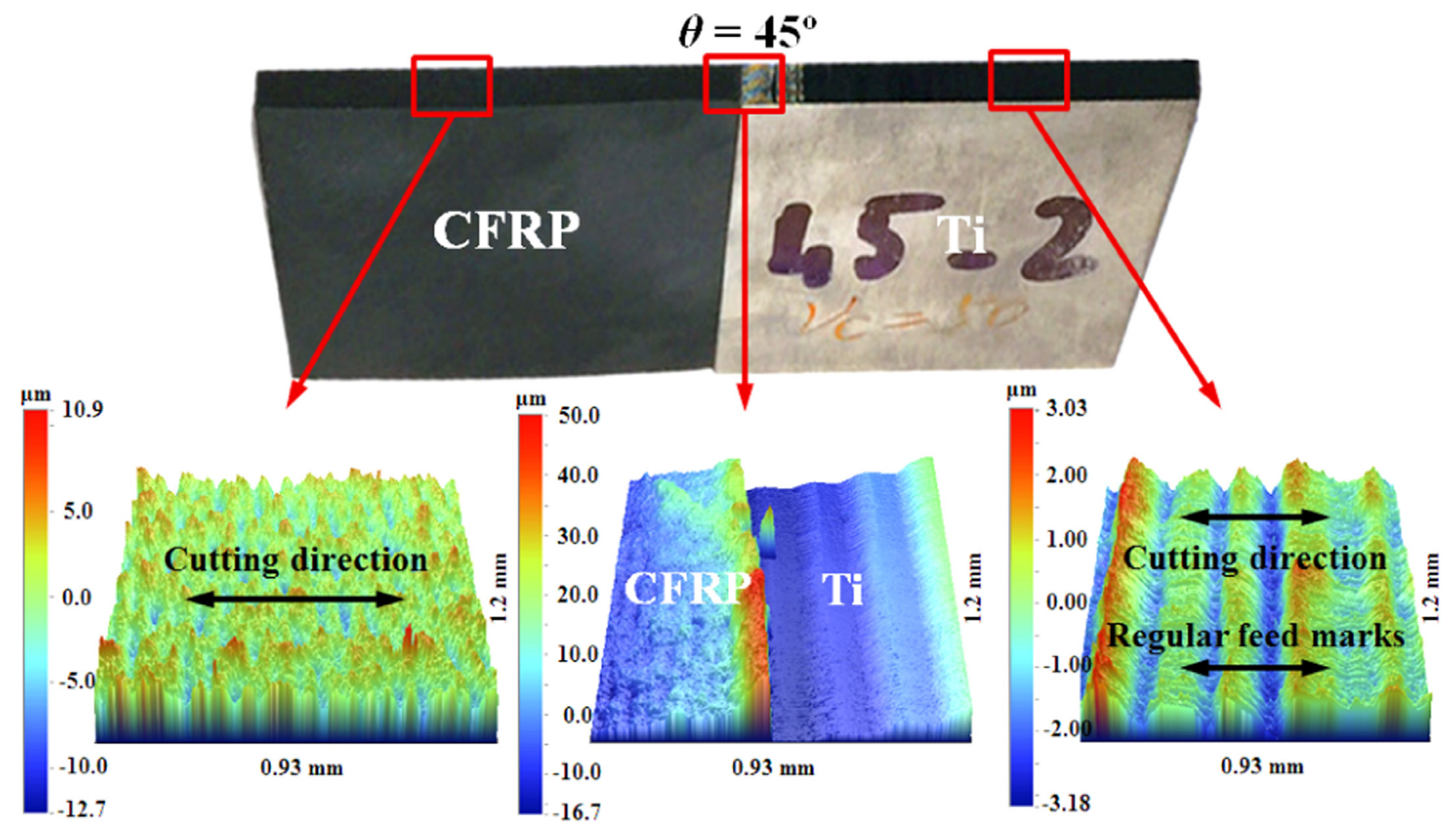

Fig. 11. Topographic maps for the trimmed CFRP/Ti surface with $45^{\circ}$ fiber orientation in the CFRP $\rightarrow$ Ti cutting sequence $\left(v_{c}=50 \mathrm{~m} / \mathrm{min}\right.$ and $\left.f=0.20 \mathrm{~mm} / \mathrm{rev}\right)$. 


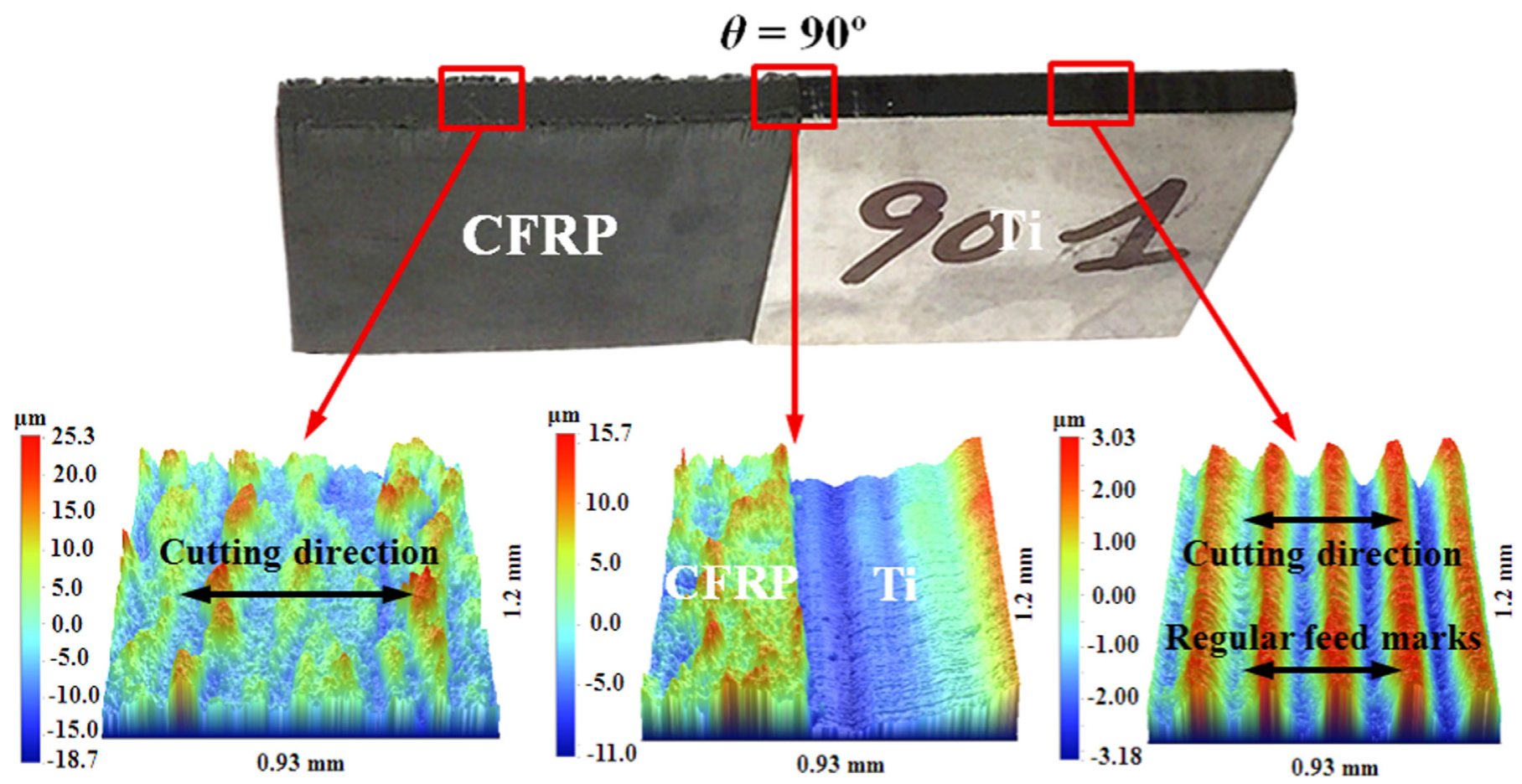

Fig. 12. Topographic maps for the trimmed CFRP/Ti surface with $90^{\circ}$ fiber orientation in the CFRP $\rightarrow$ Ti cutting sequence $\left(v_{c}=50 \mathrm{~m} / \mathrm{min}\right.$ and $\left.f=0.20 \mathrm{~mm} / \mathrm{rev}\right)$.

deformation of the trimmed Ti surfaces after suffering severe ploughing or shearing actions resulting from the hard sticking and sliding of the tool flank face. The phenomenon may imply that severe strain hardening occurs in the trimmed Ti surface. The relevant discussion is presented in Section 3.4. The interface linking the metallic phase and composite phase suffers more serious subsurface damage especially when a higher fiber orientation is used. Further, the trimmed CFRP surface with a lower fiber orientation $\left(\theta=0^{\circ}\right)$ often shows a much flatter topography as compared with that having a higher fiber orientation (e.g., $\theta=45^{\circ}$ and $90^{\circ}$ ). This can be attributed to the easier chip separation and lower cutting forces in cutting a lower $\theta$ configured CFRP/Ti as already discussed in Sections 3.1 and 3.2. Moreover, the topographic observation entirely agrees well with the findings of the SEM examination as illustrated earlier.

With regard to the $\mathrm{Ti} \rightarrow$ CFRP cutting sequence, apart from the similarly observed damage modes for the machined Ti surface and CFRP surface, one key difference is noticed for the trimmed surface morphology near the interface region. As depicted in Fig. 13, for the $0^{\circ} \mathrm{CFRP} / \mathrm{Ti}$ workpiece, a very thin Ti-phase zone with quite disparate surface morphologies compared with the regularly machined $\mathrm{Ti}$ surface is found close to the interface region. The aforementioned Ti surface zone is characterized by highly rough and uneven texture with an approximately $0.5 \mathrm{~mm}$ width. The observed dissimilar surface morphologies of the identical Ti phase should indicate the changes of the Ti chip separation mode near the interface zone. Moreover, through the magnified view of the rough zone, it is interesting to note that various small "alveolate" dimples are formed in zone $\mathrm{B}$ close to the interface region as shown in Fig. 13(b). The physical phenomenon confirms the occurrence of the rapid ductile fracture on the thin and rough zone. Besides, it is identified that the small dimples mainly take place with a higher density close to the interface zone having a width of approximately $0.18 \mathrm{~mm}$. In contrast, only very minor dimples are observed in zone A far from the CFRP/Ti interface through the SEM analyses. The findings probably indicate the transition of the $\mathrm{Ti}$ chip separation mode from elastic-plastic deformation to rapid ductile fracture in zone A. The activated mechanisms can be

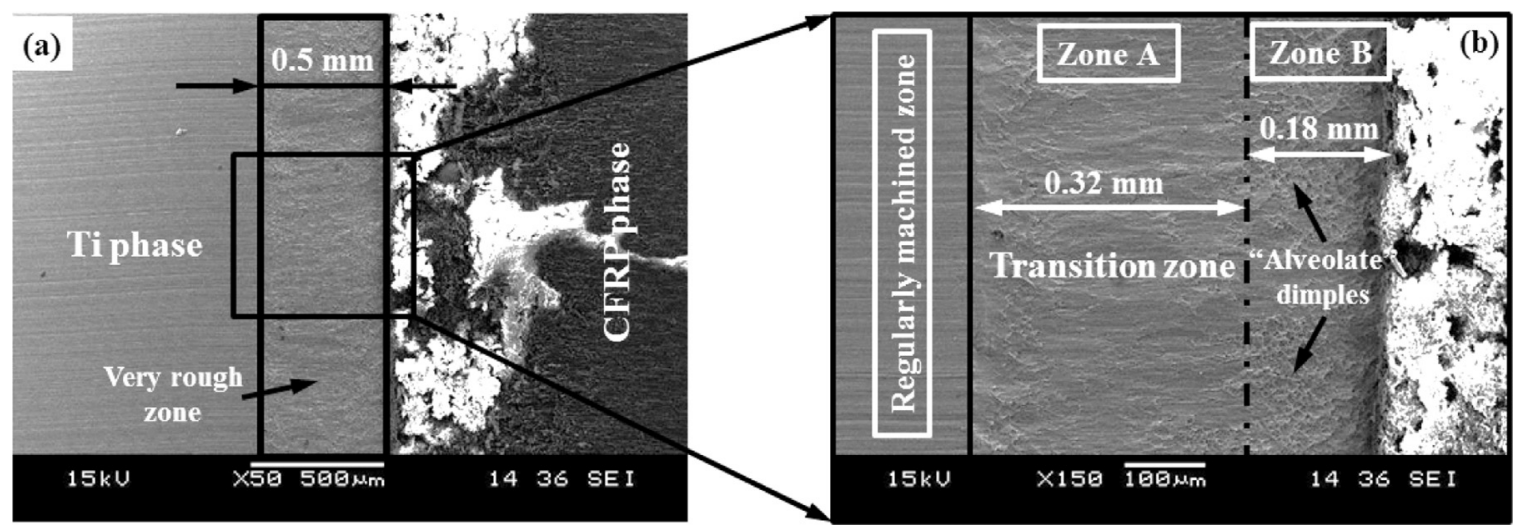

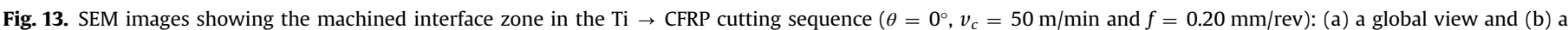
magnified view of the trimmed Ti surface near the interface region. 

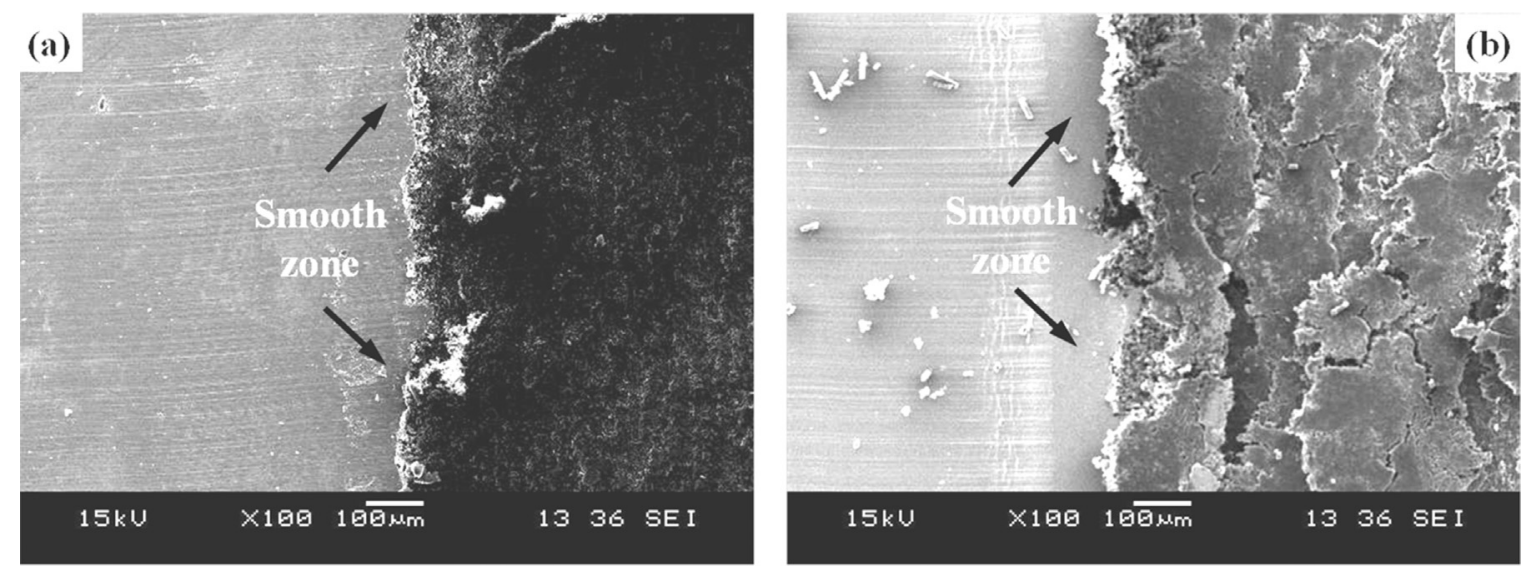

Fig. 14. SEM images showing the machined interface zones in the Ti $\rightarrow$ CFRP cutting sequence $\left(v_{c}=50 \mathrm{~m} / \mathrm{min}\right.$ and $\left.f=0.20 \mathrm{~mm} / \mathrm{rev}\right):(\mathrm{a}) \theta=45^{\circ}$ and $(\mathrm{b}) \theta=90^{\circ}$.

attributed to the varying cutting behavior of the interface zone due to the relative brittleness of the composite phase. Moreover, it can be estimated that the appearance of the rapid ductile fracture zone will greatly deteriorate the surface finish of the interface region. In addition, with respect to the $45^{\circ}$ and $90^{\circ} \mathrm{CFRP} / \mathrm{Ti}$ specimens, the regime of the rapid ductile fracture is not so clear as shown in Fig. 14.

\subsection{Surface roughness and microhardness}

In this section, the machined surface quality including surface roughness and microhardness was examined with respect to the used cutting parameters and cutting sequence strategies. The most-used surface roughness parameters $\left(R_{a}, R_{q}\right.$, and $\left.R_{z}\right)$ were adopted for the quantitative analyses. Note that the surface roughness was measured on individual CFRP surface, interface and Ti surface by using a Veeco white-light interferometer (Wyko $3300 \mathrm{NT}$ ) with a total scanning area of $0.93 \mathrm{~mm} \times 3.6 \mathrm{~mm}$.

Figs. 15-17 present the acquired values of the $R_{a}, R_{q}$, and $R_{z}$ parameters after the orthogonal cutting of CFRP/Ti. Results show that the measured arithmetic mean roughness $\left(R_{a}\right)$ values of the trimmed Ti surfaces are much lower than those of the machined CFRP surfaces, confirming the better surface finish of the machined Ti phase. Besides, the observation also agrees with the SEM and topography analyses of the trimmed CFRP/Ti surfaces. In addition, the $R_{a}$ obtained in the CFRP/Ti interface region usually shows the highest value. The phenomenon indicates the highly uneven and rough surface profile generated in the interface zone. Moreover, for the machined Ti surface, the cutting speed $\left(v_{c}\right)$ appears to have a negative impact on $R_{a}$ and $R_{q}$, while the feed rate (f) shows a totally positive impact, i.e., an increased $f$ leads to the elevated $R_{a}$ and $R_{q}$ parameters. By contrast, the parametric effect on machined CFRP surface roughness is obscure, and the variation law is not very noticeable. Further, the comparative results shown in Fig. 18 also reveal the positive effect of the fiber orientation $(\theta)$ on the generated surface finish. For instance, it can be observed that when machining a higher $\theta$ configured CFRP/Ti stack, the measured $R_{a}$ parameter of the trimmed CFRP surface increases dramatically from the minimum value of $1.80 \mu \mathrm{m}$ for the $0^{\circ}$ fiber orientation to the maximum value of $3.63 \mu \mathrm{m}$ for the $90^{\circ}$ fiber orientation under the identical cutting conditions of $v_{c} \mathrm{~m} / \mathrm{min}$ and $f=0.20 \mathrm{~mm} / \mathrm{rev}$. The phenomenon may be induced by the formation of severe subsurface damage when the fiber orientation is elevated.

In addition, to clarify the influences of different cutting sequence strategies on the machined CFRP/Ti surface finish, a comparative study of the $R_{a}$ results is shown in Fig. 19 for cutting $\theta=$ $0^{\circ}$ CFRP/Ti stacks. It is noticeable that the measured $R_{a}$ values of the trimmed CFRP surfaces in the $\mathrm{Ti} \rightarrow$ CFRP cutting sequence seem much higher than those gained in the CFRP $\rightarrow$ Ti cutting sequence, irrespective of the used cutting conditions. This can be attributed to the serious Ti chip adhesion on tool rake face that substitutes the tool edge for further CFRP phase cutting as discussed earlier in Section 3.1. In contrast, using the $\mathrm{Ti} \rightarrow$ CFRP cutting sequence can ensure a fresh cutting edge to cut initially the Ti phase, thereby promoting a lower surface roughness value of the machined Ti surface. Besides, the trimmed interface in the Ti $\rightarrow$ CFRP cutting sequence shows the poorer surface finish (i.e., a

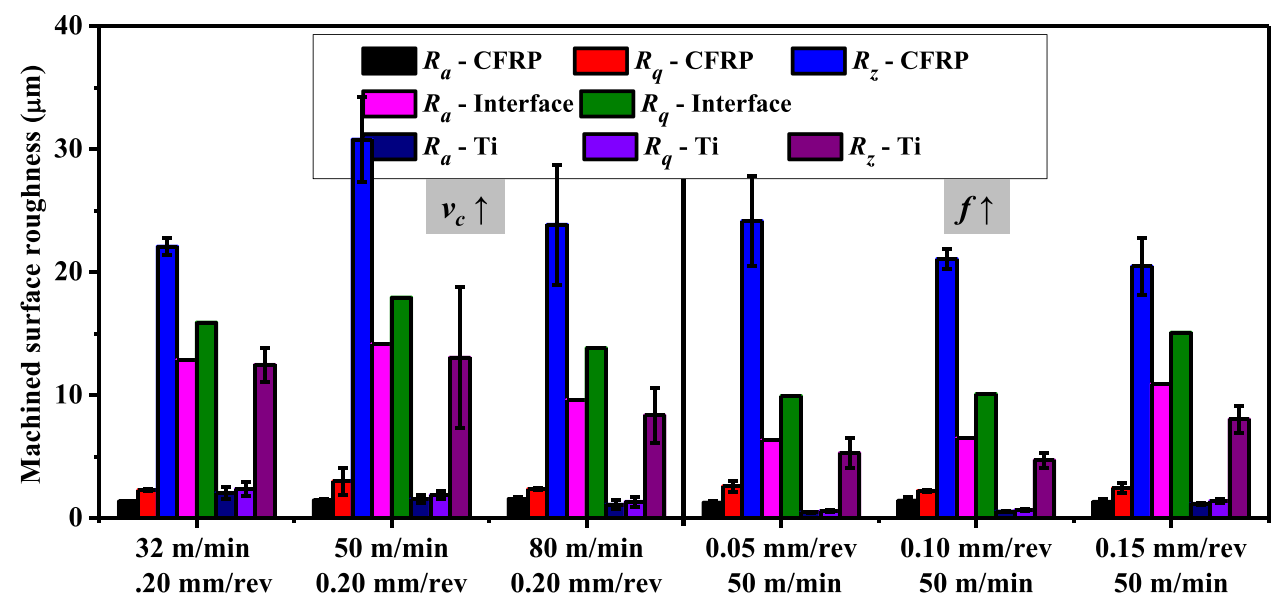

Fig. 15. Variations of the measured $R_{a}, R_{q}$ and $R_{z}$ parameters for the trimmed $\theta=0^{\circ} \mathrm{CFRP} / \mathrm{Ti}$ surfaces in the CFRP $\rightarrow$ Ti cutting sequence. 


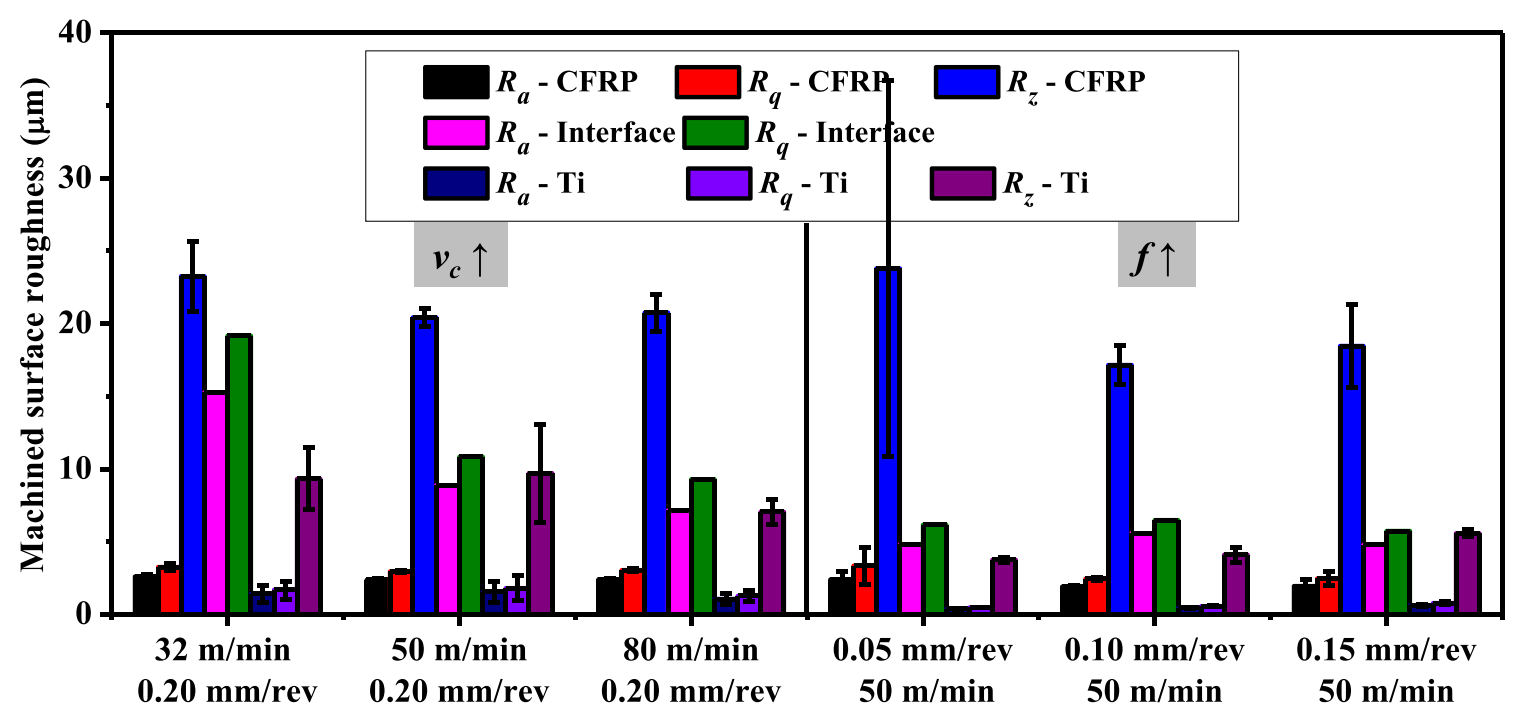

Fig. 16. Variations of the measured $R_{a}, R_{q}$ and $R_{z}$ parameters for the trimmed $\theta=45^{\circ} \mathrm{CFRP} / \mathrm{Ti}$ surfaces in the CFRP $\rightarrow$ Ti cutting sequence.

higher $R_{a}$ value) compared with that machined in the CFRP $\rightarrow \mathrm{Ti}$ cutting as depicted in Fig. 19. This observation also confirms the occurrence of the rapid ductile fracture zone close to the interface region, which leads to the highly rough machined surface as discussed in Section 3.3.

Furthermore, the microhardness of the machined Ti phase in the CFRP $\rightarrow$ Ti cutting sequence was measured with respect to different cutting conditions as depicted in Fig. 20. The cutting speed $\left(v_{c}\right)$ and feed rate $(f)$ are found to have a negative impact on the microhardness of the trimmed metallic surfaces. When the cutting is operated under the low feed-rate conditions, e.g., $f$ $=0.05 \mathrm{~mm} / \mathrm{rev}$, the measured microhardness values are all higher than the bulk hardness ( $355 \mathrm{HV}_{0.10}$ ) of the Ti alloy for all the used fiber orientations $(\theta)$, indicating the occurrence of the strain hardening on the trimmed metallic surfaces. With the increase of the feed rate, the strain hardening effects decrease gradually and result in the reduced microhardness. In contrast, when using the high-speed conditions, e.g., $v_{c}=80 \mathrm{~m} / \mathrm{min}$, the machined Ti surface of the $\theta=0^{\circ} \mathrm{CFRP} / \mathrm{Ti}$ stack can yield a microhardness value of $341.9 \mathrm{HV}_{0.10}$ lower than the bulk hardness of Ti6Al4V. The phenomenon clearly indicates the occurrence of the thermal softening on the trimmed Ti surface when the cutting speed is elevated.

\subsection{Tool wear}

To clarify the effects of the fiber orientation $(\theta)$ on the wear characteristics of the PCD tool, each $\theta$ configured CFRP/Ti specimen $\left(\theta=0^{\circ}, 45^{\circ}\right.$, and $\left.90^{\circ}\right)$ was cut with a new PCD tipped insert under the identical cutting conditions $\left(v_{c}=50 \mathrm{~m} / \mathrm{min}\right.$ and $f=$ $0.20 \mathrm{~mm} / \mathrm{rev}$ ) in order to eliminate the influences of tool wear and cutting parameters. Figs. 21 and 22 show the wear morphologies of the worn PCD tipped insert after cutting $0^{\circ}$ CFRP/Ti stacks. Results indicate that a large white strip zone with an area of approximately $0.42 \mathrm{~mm} \times 4.53 \mathrm{~mm}$ exists on the tool rake face, which signifies the actual crater wear land and the tool-chip interaction area during the chip removal process. Besides, it is also worth mentioning that the major contribution to the large crater wear zone should be the Ti alloy cutting since the CFRP cutting has very minor effects on tool crater wear formation due to the insignificant or nonexistent contribution of secondary shear zone in heat generation resulting from the brittle-fracture dominated chip separation as pointed out by several research studies $[13,14]$. In the Ti alloy cutting, the predominant chip separation is elasticplastic deformation characterized by the "continuous" or "serrated" chip formation, which consequently results in a longer tool-chip contact length. In contrast, the CFRP cutting is governed by the brittle fracture with "powdery" chip formation as discussed earlier in Section 3.1, and hence the chip separation should contribute

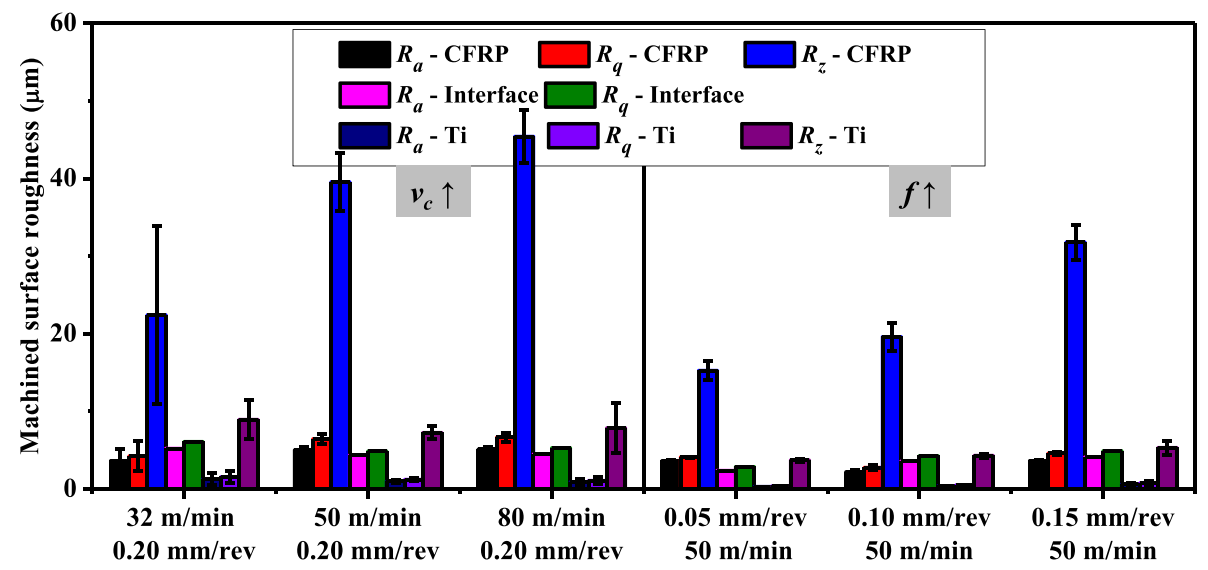

Fig. 17. Variations of the measured $R_{a}, R_{q}$ and $R_{z}$ parameters for the trimmed $\theta=90^{\circ} \mathrm{CFRP} / \mathrm{Ti}$ surfaces in the CFRP $\rightarrow$ Ti cutting sequence. 


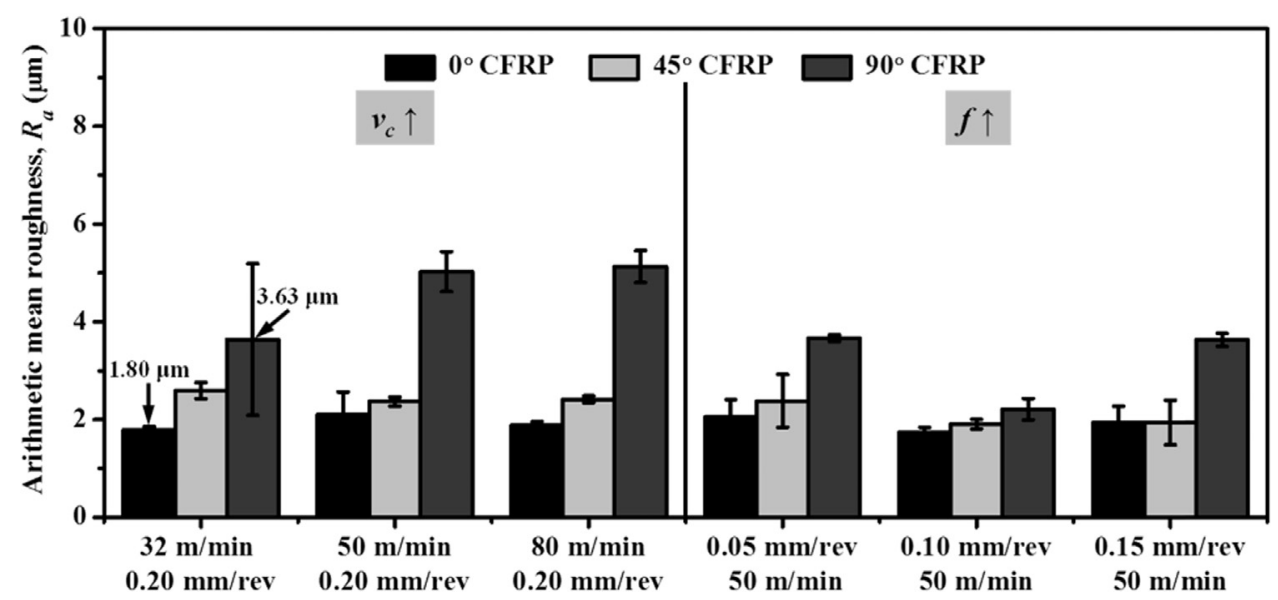

Fig. 18. Comparative $R_{a}$ values of the machined CFRP surfaces with different fiber orientations $(\theta)$ in the CFRP $\rightarrow$ Ti cutting sequence.

less to the formation of the tool crater wear zone. Besides, along the cutting edge, the catastrophic failure of edge chipping is also detected on the examined PCD tool, which should be attributed to the sudden force variation resulting from the CFRP/Ti interface machining and the inherent brittleness of the PCD material. Further, since the Ti alloy shows a strong chemical affinity to mostused tool materials, a large amount of titanium is identified on the tool rake face as depicted in Fig. 21, confirming the occurrence of adhesion wear.

Moreover, the optical microscope analysis on the tool flank face also reveals that the PCD tipped cutting zone has suffered a very minor flank wear land after the completion of the orthogonal cutting tests owing to the high wear resistance and high hardness of the PCD material. Meanwhile, the micro chipping (edge fracture) is identified along the flank wear land through the SEM observation (Ref. Fig. 22), which may greatly deteriorate the tool edge sharpness and make the tool completely lose its cutting capability.

Besides, during the cutting of other $\theta$ configured CFRP/Ti specimens, the similar tool wear modes and wear morphologies are observed as depicted in Figs. 23 and 24. The key difference between the observed tool wear morphologies can be reflected in the width of the crater wear land, which in reality signifies the real contact length of the tool-chip interaction during the CFRP/Ti machining. As shown in cutting the $90^{\circ} \mathrm{CFRP} / \mathrm{Ti}$ specimen, the width of tool crater wear land is promoted around $0.50 \mathrm{~mm}$, while for $0^{\circ}$ and $45^{\circ}$ specimens the crater wear width is $0.42 \mathrm{~mm}$ and $0.41 \mathrm{~mm}$, respectively. Since the same cutting length and identical fresh PCD tool are used for each cutting test, the physical phenomena should indicate that the different fiber orientations of the stacked CFRP phase indeed have a significant influence on modifying the geometrical feature of the tool active zone. As illustrated earlier in Section 3.1, in cutting different $\theta$ configured unidirectional (UD) laminates, the tool-chip contact length usually varies due to the different fiber/matrix separation modes occurring at the tool-chip interface. When cutting a higher $\theta$ configured UD-CFRP laminate, e.g., $\theta=90^{\circ}$, commonly a longer tool-chip contact length is formed. Therefore, when the tool edge initially attacks the CFRP phase, the carbon fibers with different fiber orientations should induce disparate extents of the crater wear width on the tool fresh rake face and then modify the tool's original geometrical feature. Consequently, when the tool cuts across the subsequent Ti phase, the final tool-chip interaction length is changed, resulting in the different crater wear widths.

\section{Conclusions}

The wear characteristics of the PCD tipped inserts in cutting CFRP/Ti stacks with different fiber orientations have been investigated using the orthogonal cutting method. Two different cutting sequence strategies were performed against various $\theta$ configured CFRP/Ti specimens. The experimental analyses involving a series of studies on the chip removal process, cutting forces, machined surface quality and tool wear signatures were

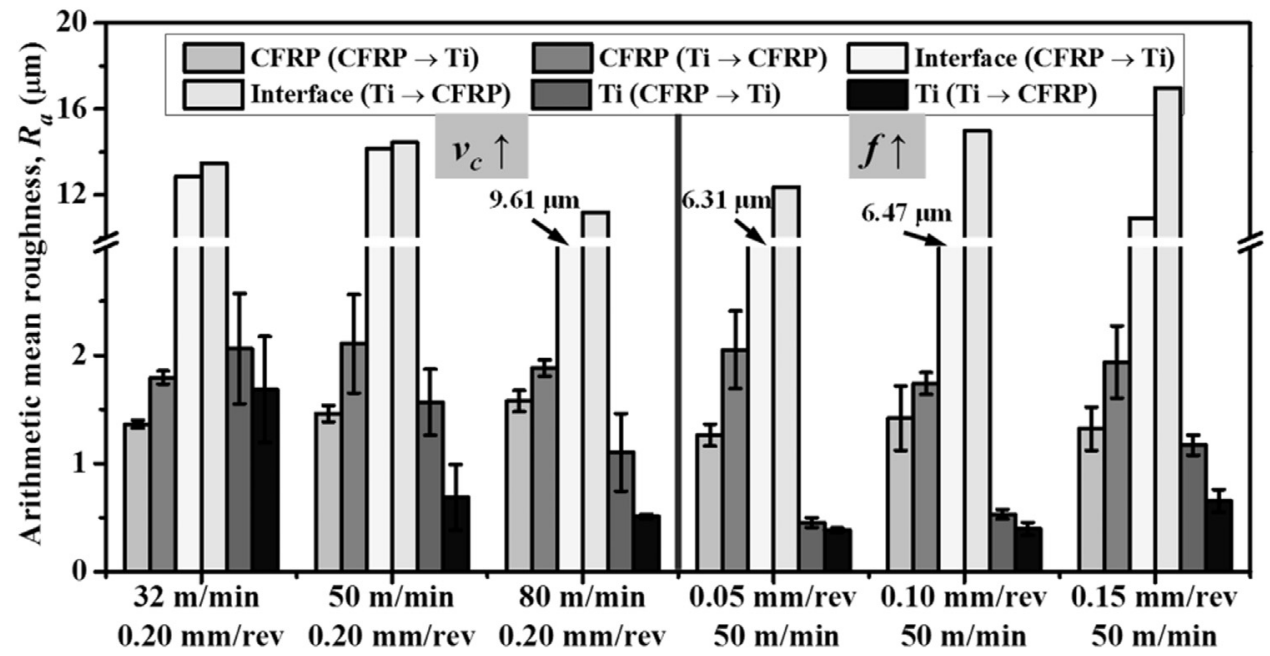

Fig. 19. Comparative $R_{a}$ values of the machined CFRP/Ti surfaces $\left(\theta=0^{\circ}\right)$ under different cutting sequence strategies. 


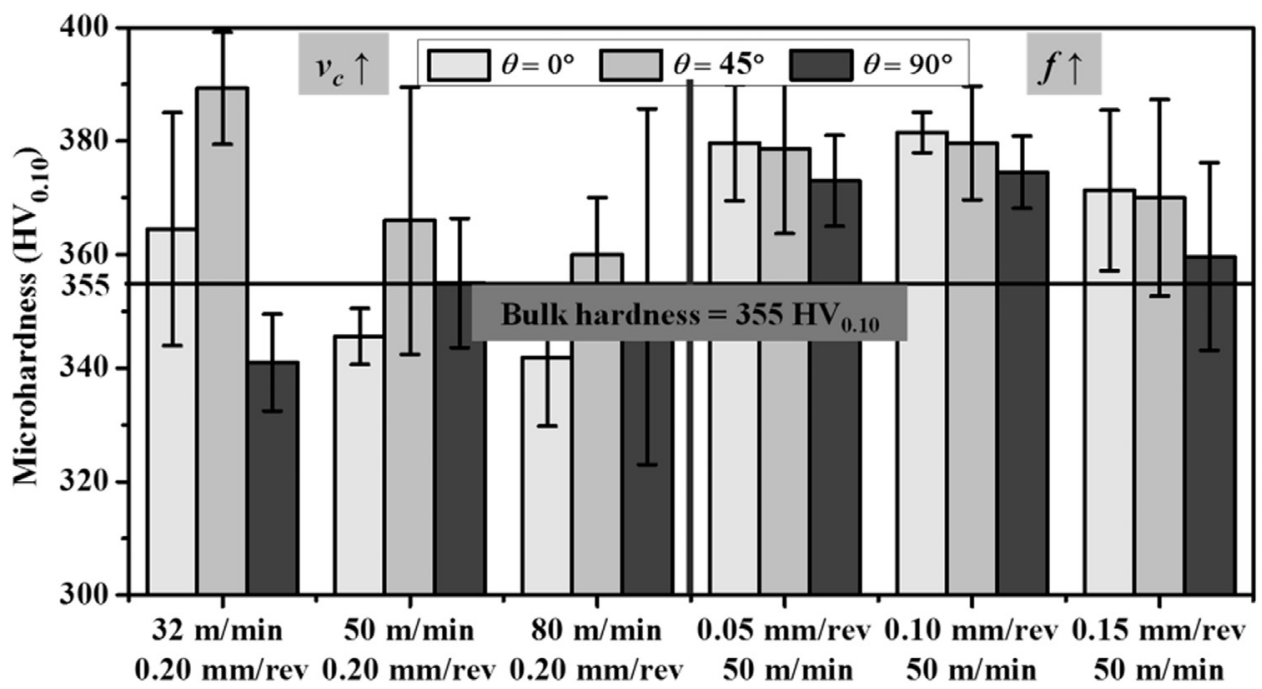

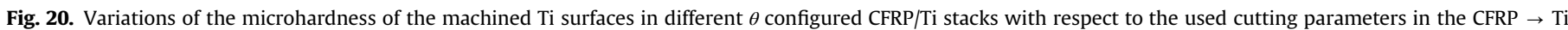
cutting sequence.
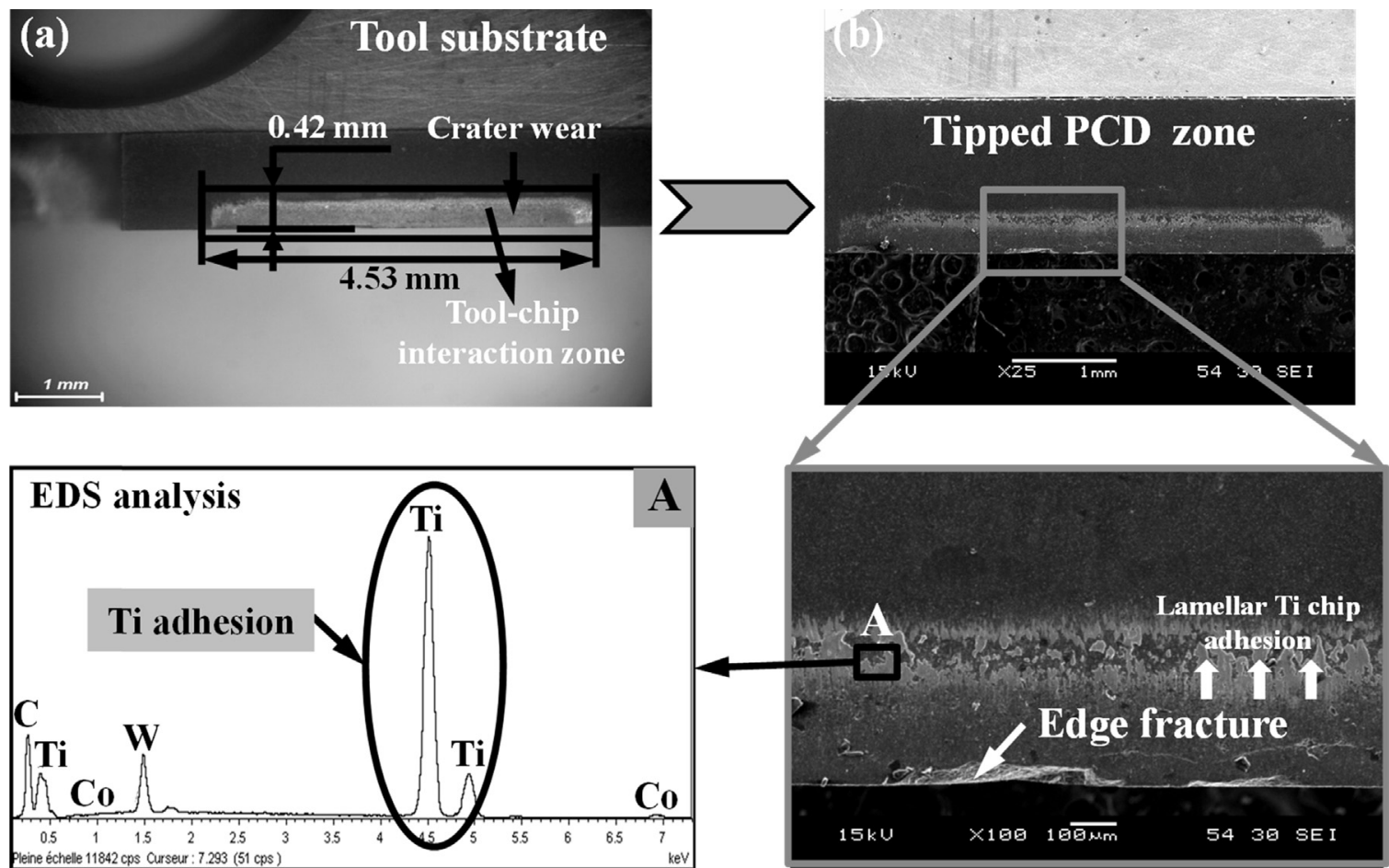

Fig. 21. Surface morphologies on the worn rake face of the used PCD tipped insert after cutting $\theta=0^{\circ} \mathrm{CFRP} / \mathrm{Ti}$ stacks: (a) an optical micrograph of the tool rake surface and (b) SEM observations of the tool crater wear zone.

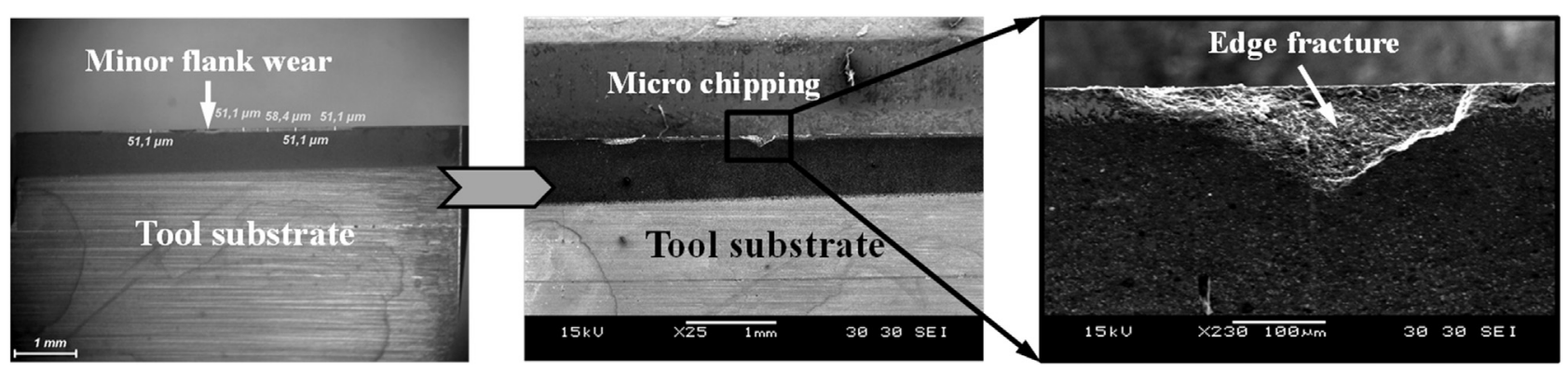

Fig. 22. Surface morphologies on the worn flank face of the used PCD tipped insert after cutting $\theta=0^{\circ} \mathrm{CFRP} / \mathrm{Ti}$ stacks. 

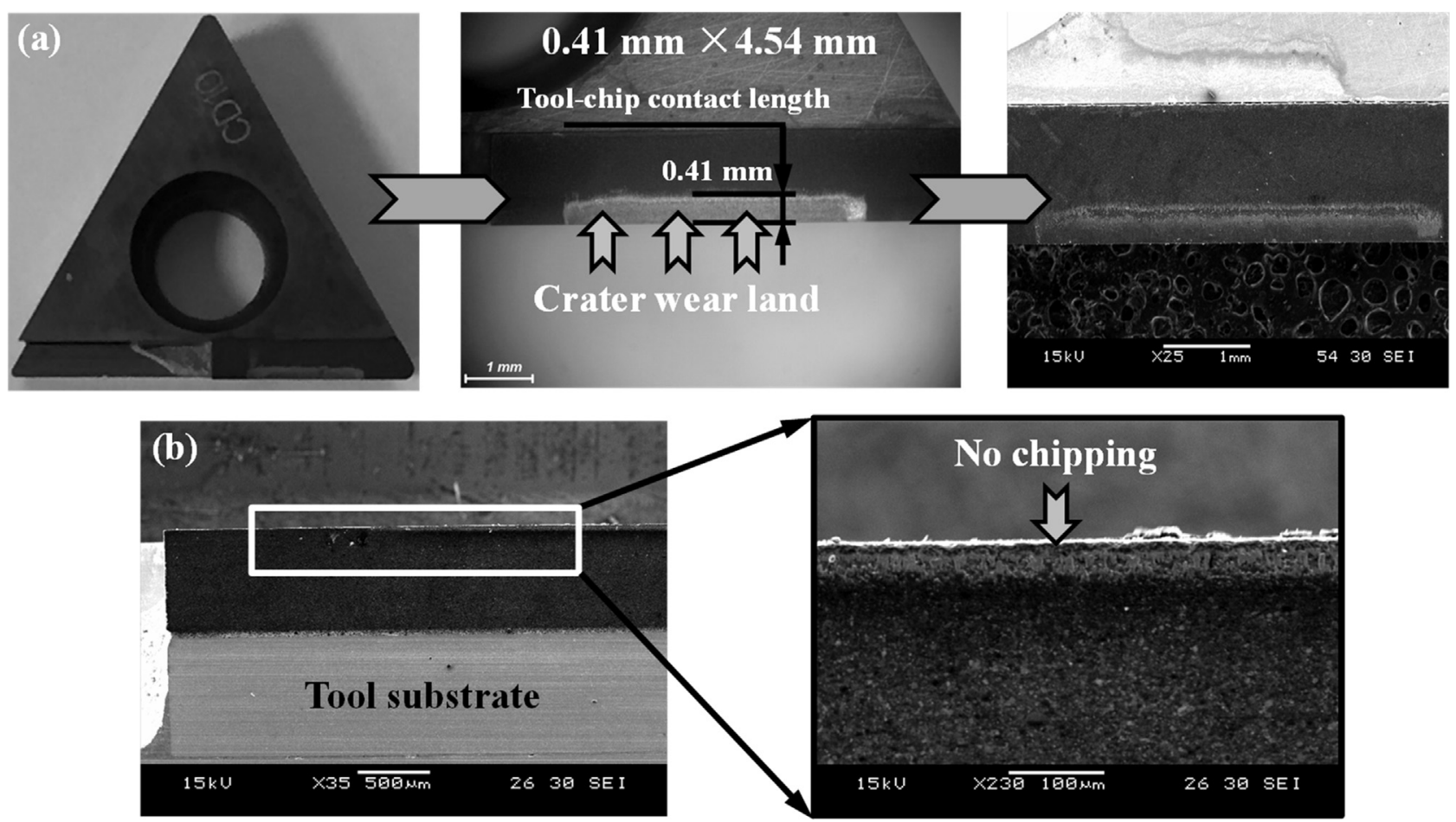

Fig. 23. Surface morphologies of the worn PCD tipped insert after cutting $\theta=45^{\circ} \mathrm{CFRP} / \mathrm{Ti}$ stacks: (a) tool rake surface and (b) tool flank surface.

conducted to highlight the mechanisms dominating the wear behavior of the utilized PCD tools. According to the experimental studies performed in the orthogonal cutting of CFRP/Ti stacks, the following conclusions can be drawn.

- The entire CFRP/Ti cutting involves both brittle fracture and elastic-plastic deformation mechanisms, resulting in the "powdery" and "continuous" like chip types. The cutting sequence strategy has a significant effect on the CFRP/Ti chip removal process and the finally machined surface quality. The Ti chip adhesion is a key cause of the "V-shape" notch delamination in the interface zone and the severe cracking damage inside the machined CFRP phase. The results also highlight that the $\mathrm{CFRP} \rightarrow$ Ti cutting sequence favors the CFRP/Ti orthogonal

\section{Tool rake face}

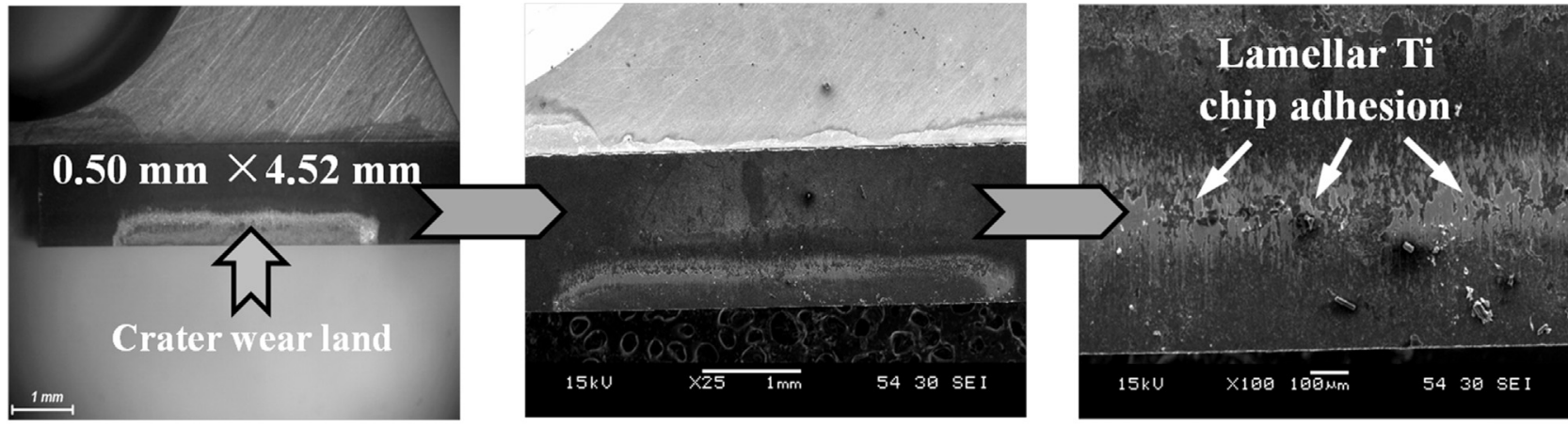

Tool flank face

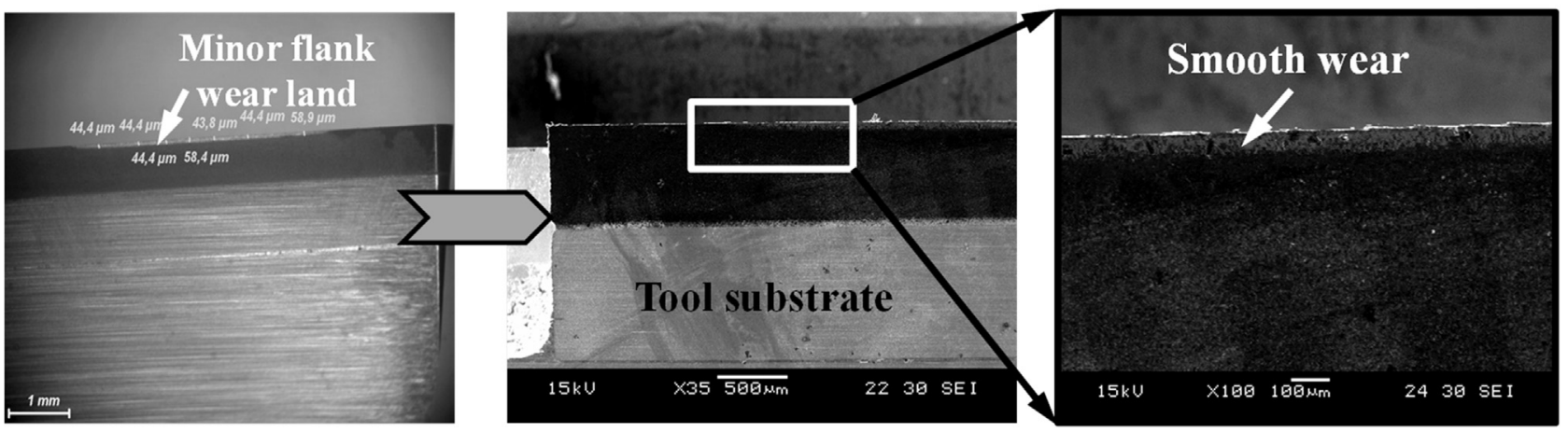

Fig. 24. Surface morphologies of the worn PCD tipped insert after cutting $\theta=90^{\circ} \mathrm{CFRP} / \mathrm{Ti}$ stacks. 
cutting due to the easier chip evacuation and the avoided effects of the serious $\mathrm{Ti}$ chip adhesion on the subsequent CFRP machining.

- The influence of the cutting speed on the CFRP/Ti cutting forces mainly depends on the competition between its effects on the tool wear progression and on the work material softening. The feed rate $(f)$ totally shows a significantly positive impact on the CFRP/Ti cutting forces. Moreover, the fiber orientation $(\theta)$ seems to have a pronounced effect on the cutting forces for the CFRP phase machining, while its influence on the cutting forces of $\mathrm{Ti}$ phase machining is negligible. To minimize the CFRP/Ti cutting forces, the low feed rates, the small fiber orientations as well as the moderate cutting speeds should be applied in the orthogonal cutting of CFRP/Ti stacks.

- The surface quality studies highlight that the cutting-induced CFRP/Ti damage mainly occurs in the CFRP phase and the interface region. The fiber orientation $(\theta)$ can be pointed out as a notable factor greatly affecting the finally machined CFRP/Ti surface morphology and surface quality. The deformation of feed marks and re-deposited chip materials constitute the key damage modes of the machined $\mathrm{Ti}$ phase, while the fiber splintering and resin loss characterize the major imperfections of the trimmed CFRP phase. The phenomenon of the rapid ductile fracture can take place near the interface region when the cutting is performed from Ti to CFRP.

- The machined CFRP/Ti surface roughness is affected significantly by the feed rate $(f)$ and fiber orientation $(\theta)$ in the two cutting sequence strategies. The Ti $\rightarrow$ CFRP cutting sequence promotes much higher CFRP surface roughness as compared with the CFRP $\rightarrow$ Ti cutting sequence since the serious Ti chip adhesion on tool rake face substitutes the tool edge for further CFRP phase chip separation. In contrast, the lower machined Ti surface roughness can be achieved by using the Ti $\rightarrow$ CFRP sequence as the fresh tool edge can initially cut into the metallic phase without the influence from the subsequent CFRP machining. Further, the microhardness analysis confirms the occurrence of the thermal softening when increasing cutting speeds and the existence of the strain hardening when changing feed rates in the CFRP/Ti orthogonal cutting.

- The PCD tipped insert suffers serious crater wear in the CFRP/Ti orthogonal cutting mainly due to the Ti phase cutting, while it undergoes minor flank wear owing to its high wear resistance. Besides, the varying crater wear width gained under the identical cutting speed and feed rate confirms the high sensitivity of the wear behavior of utilized PCD tools to the fiber orientation $(\theta)$ of the CFRP phase. The phenomenon should be induced by the different extents of tool geometrical alterations on the tool active zone during the cutting of different $\theta$ configured CFRP/Ti specimens.

- The experimental results discussed in this paper have provided some implications on the orthogonal cutting of CFRP/Ti stacks. One key point which can be drawn in this study is that in the CFRP/Ti orthogonal cutting, particular attention should be paid to the challenging interface cutting and the careful selection of the cutting sequence strategy. The manufacturing sectors also need to develop a particular process for cutting this bi-material structure such as using low feed rates, moderate cutting speeds and the CFRP $\rightarrow$ Ti cutting sequence in order to achieve excellent machined surface quality. Besides, the PCD tool is confirmed to yield a better performance in the CFRP phase cutting due to its high wear resistance against abrasive carbon fibers, while it seems unsuitable for cutting the Ti phase because of the serious crater wear and adhesion wear. In the future, the advanced tool materials, which can meet both the CFRP cutting and Ti cutting, should be utilized in cutting this multilayer material.

\section{Acknowledgements}

The authors gratefully acknowledge the financial support of the China Scholarship Council (CSC) (Contract No. 201306230091). The authors also would like to thank Mr. Julien Voisin for his technical assistance throughout the experiments.

\section{References}

[1] M. Ramulu, T. Branson, D. Kim, A study on the drilling of composite and titanium stacks, Compos. Struct. 54 (2001) 67-77, http://dx.doi.org/10.1016/ S0263-8223(01)00071-X.

[2] K.H. Park, A. Beal, D. Kim, P. Kwon, J. Lantrip, Tool wear in drilling of composite/titanium stacks using carbide and polycrystalline diamond tools, Wear 271 (2011) 2826-2835, http://dx.doi.org/10.1016/j.wear.2011.05.038.

[3] X. Wang, P.Y. Kwon, C. Sturtevant, D. Kim, J. Lantrip, Comparative tool wear study based on drilling experiments on CFRP/Ti stack and its individual layers, Wear 317 (2014) 265-276, http://dx.doi.org/10.1016/j.wear.2014.05.007.

[4] J. Xu, A. Mkaddem, M. El Mansori, Recent advances in drilling hybrid FRP/Ti composite: a state-of-the-art review, Compos. Struct. 135 (2016) 316-338, http://dx.doi.org/10.1016/j.compstruct.2015.09.028.

[5] J. Xu, M. El Mansori, Experimental study on drilling mechanisms and strategies of hybrid CFRP/Ti stacks, Compos. Struct. 157 (2016) 461-482, http://dx.doi. org/10.1016/j.compstruct.2016.07.025.

[6] C.L. Kuo, S.L. Soo, D.K. Aspinwall, S. Bradley, W. Thomas, R. M'Saoubi, D. Pearson, W. Leahy, Tool wear and hole quality when single-shot drilling of metallic-composite stacks with diamond-coated tools, Proc. Inst. Mech. Eng. Pt. B-J. Eng. Manuf. 228 (2014) 1314-1322, http://dx.doi.org/10.1177/ 0954405413517388.

[7] D. Kim, M. Ramulu, Drilling process optimization for graphite/bismaleimidetitanium alloy stacks, Compos. Struct. 63 (2004) 101-114, http://dx.doi.org/ 10.1016/S0263-8223(03)00137-5.

[8] O. Isbilir, E. Ghassemieh, Comparative study of tool life and hole quality in drilling of CFRP/titanium stack using coated carbide drill, Mach. Sci. Technol. 17 (2013) 380-409, http://dx.doi.org/10.1080/10910344.2013.806098.

[9] T. Tashiro, J. Fujiwara, K. Inada, Drilling of CFRP/Ti-6Al-4V stacks, Adv. Mater. Res. 325 (2011) 369-374, http://dx.doi.org/10.4028/www.scientific.net/ AMR.325.369.

[10] R. Garrick, Drilling advanced aircraft structures with PCD (poly-crystalline diamond) drills, AeroTech Congress \& Exhibition, Los Angeles, CA, USA 2007 pp. 1-9, http://dx.doi.org/10.4271/2007-01-3893.

[11] J. Xu, M. El Mansori, Experimental studies on the cutting characteristics of hybrid CFRP/Ti stacks, Procedia Manuf. 5 (2016) 270-281, http://dx.doi.org/ 10.1016/j.promfg.2016.08.024.

[12] A. Ben Soussia, A. Mkaddem, M. El Mansori, Rigorous treatment of dry cutting of FRP - interface consumption concept: a review, Int. J. Mech. Sci. 83 (2014) 1-29, http://dx.doi.org/10.1016/j.ijmecsci.2014.03.017.

[13] C.-S. Chang J-E. Ho, C.-H. Chan, B.-C. Hwang Prediction of cutting temperatures in turning carbon fiber reinforced plastics composites with worn tools, J. Appl. Sci. 11 (2011) 3698-3707, http://dx.doi.org/10.3923/jas.2011.3698.3707.

[14] A. Mkaddem, A. Ben Soussia, M. El Mansori, Wear resistance of CVD and PVD multilayer coatings when dry cutting fiber reinforced polymers (FRP), Wear 302 (2013) 946-954, http://dx.doi.org/10.1016/j.wear.2013.03.017. 